\title{
Characterisation of arginase paralogues in salmonids and their modulation by immune stimulation/ infection
}

Ottavia Benedicenti ${ }^{\text {a,b }}$, Tiehui Wang ${ }^{\text {a }}$, Eakapol Wangkahart ${ }^{\text {a }}$, Douglas J. Milne ${ }^{\text {a }}$, Jason W. Holland ${ }^{\text {a }}$, Catherine Collins ${ }^{\text {b }}$, Christopher J. Secombes *a 
Abstract

In this study we show that four arginase isoforms ( $\arg 1 a, \arg 1 b, \arg 2 a, \arg 2 b)$ exist in rainbow trout (Oncorhynchus mykiss) and Atlantic salmon (Salmo salar). We have characterised these molecules in terms of a) sequence analysis, b) constitutive expression in different tissues, and modulated expression following c) stimulation of head kidney macrophages in vitro, or d) vaccination/ infection with Yersinia ruckeri and e) parasite infection (AGD caused by Paramoeba perurans and PKD caused by Tetracapsuloides bryosalmonae). Synteny analysis suggested that these arginase genes are paralogues likely from the Ss4R duplication event, and amino acid identity/ similarity analyses showed that the proteins are relatively well conserved across species. In rainbow trout constitutive expression of one or both paralogues was seen in most tissues but different constitutive expression patterns were observed for the different isoforms. Stimulation of rainbow trout head kidney macrophages with PAMPs and cytokines also revealed isoform specific responses and kinetics, with argla being particularly highly modulated by the PAMPs and proinflammatory cytokines. In contrast the type II arginase paralogues were induced by rIl-4/13, albeit to a lesser degree. Vaccination and infection with $Y$. ruckeri also revealed isoform specific responses, with variation in tissue expression level and kinetics. Lastly, the impact of parasite infection was studied, where down regulation of $\operatorname{argla}$ and $\arg l b$ was seen in two different models (AGD in salmon and PKD in trout) and of arg2a in AGD. The differential responses seen are discussed in the context of markers of type II responses in fish and paralogue subfunctionalisation.

Keywords: arginase paralogues; Oncorhynchus mykiss; Salmo salar; macrophages; vaccination; parasite infections. 
Arginase (amidinohydrolase, EC 3.5.3.1) is an ureohydrolase enzyme widely distributed in living organisms, from bacteria and yeast to plants and animals [1,2]. It catalyses the conversion of L-arginine into L-ornithine plus urea in the Krebs-Henselheit urea cycle. Most studied microorganisms and invertebrates have only one type of arginase, localized in the mitochondria [2,3]. Arginase gene duplication occurred after the separation of vertebrates and invertebrates with the appearance of a cytosolic arginase in ureotelic animals [1-3]. These two isoforms have been studied extensively in mammals and are termed arginase type I and

type II. Type I is the cytoplasmic form and is expressed in liver as part of the urea cycle whilst type II is the mitochondrial associated enzyme which is expressed in several peripheral tissues but primarily in the kidney, prostate, small intestine and lactating glands [4]. Hence the two enzymes catalyse the same biochemical reaction but differ in cellular expression, regulation and subcellular localization $[1,4]$.

Within the immune system arginase is known to be a marker of type II responses that are broadly anti-inflammatory and associated with tissue healing, as seen in parasite infections. In the classical polarisation model, activated macrophages can either 1) convert L-arginine to L-citrulline and produce nitric oxide (NO)/ reactive nitrogen species by the action of inducible nitric oxide synthase (iNOS) after stimulation by T helper 1 (Th1) cytokines such as interferon (IFN)- $\gamma$, or 2) they can express arginase after activation with Th2 cytokines including interleukin (IL)-4, IL-10 and IL-13 [4] thereby generating the "repair" molecule ornithine that is involved in polyamine and collagen biosynthesis, the latter an important extracellular matrix component that promotes tissue remodelling/ fibrosis during healing. These polarized macrophage populations are referred to as classically activated (M1) or alternatively activated (M2) cells respectively. More recently it has become apparent that M1 and M2 may represent extremes of a large array of activation states and that polarization of macrophages first during an innate immune response likely directs $\mathrm{T}$ cells to produce Th1 or Th2 adaptive responses, where their secreted cytokines serve to amplify the macrophage dichotomy [5].

M2 macrophages with elevated levels of arginase activity have also been found in fish [5-8]. Common carp (Cyprinus carpio) infected with Trypanosoma carassii show elevated levels of arginase enzyme activity during the later phase of infection and lack a prominent NO response. Moreover, stimulation of head kidney leukocytes from T. carassii infected carp with dibutyryl cyclic adenosine mono phosphate (cAMP, $0.5 \mathrm{mg} / \mathrm{ml}$ ) increases arginase 
activity 3-4 fold but these same cells do not increase nitrite production after lipopolysaccharide (LPS, $50 \mathrm{mg} / \mathrm{ml}$ ) stimulation [7]. Similar findings were obtained with macrophage cultures from uninfected fish stimulated with cAMP but now LPS induced iNOS expression and nitrite production [9, 10]. Modulation of arginase gene expression has also been shown in salmonids during parasite infection. Arginase type I is up regulated in skin of Atlantic salmon (Salmo salar) infected with sea lice (Lepeophtheirus salmonis) [6] but is down regulated in posterior kidney after Tetracapsuloides bryosalmonae infection in rainbow trout (Oncorhynchus mykiss) and in gills of salmon after Paramoeba perurans infection [11, 12]. Functional divergence of arginase type I and arginase type II in fish vs mammals has been recently hypothesized in common carp, where it is suggested that arginase type II is a better marker for alternatively activated macrophages in teleost fish rather than arginase type I [5].

A whole-genome duplication (WGD) event occurred at the base of the teleost fish during evolution, and a further WGD (the Ss4R salmonid-specific autotetraploidization event) occurred in the common ancestor of salmonids about 80 Mya after their divergence from Esociformes $[13,14]$. Following genome duplication events, duplicated genes can either be lost by pseudogenization or retained as two copies that can diverge by the partitioning of the ancestral gene functions (i.e. subfunctionalization) or by the acquisition of a novel function (i.e. neofunctionalization) [15]. In rainbow trout and Atlantic salmon four different isoforms of arginase $(\operatorname{argla}, \arg 1 b, \arg 2 a, \arg 2 b)$ have been found in this study, which has characterised these molecules in terms of sequence analysis, constitutive expression in different tissues, and modulated expression following stimulation of cultured head kidney macrophages in vitro or after vaccination and/ or infection in vivo.

\section{Materials and methods}

\subsection{Cloning of arginase isoforms and sequence analysis}

The rainbow trout whole genome shotgun (WGS) sequence was searched with tBLASTn [16], using fish Arginase I and II protein sequences. Candidate WGS contigs (contigs 25562, arginase 1a; 44798, arginase $1 b ; 119897$, arginase $2 a$; and 23604, arginase $2 b$ ) were identified and exons predicted as described previously [17, 18]. Primers (Table 1) were designed to the 5'- and 3'- untranslated regions (UTR) and used for PCR amplification and cloning of the complete coding region using a mixed tissue cDNA sample. The cloning, DNA and protein sequence analysis was as described previously [19, 20]. Briefly, the nucleotide sequences generated were assembled and analysed using the AlignIR ${ }^{\mathrm{TM}}$ Software (LI-COR, 
Inc.). The translated trout protein sequences were used to find the four different isoforms in Atlantic salmon in SalmoBase (http://salmobase.org) using BLAST search (tBLASTn). The Atlantic salmon amplified products obtained using newly designed primers were confirmed by cloning and sequence analysis. Briefly, the PCR products were cloned into pGEM®-T Easy Cloning Vector (Promega) and transformed into competent Escherichia coli cells (RapidTrans ${ }^{\mathrm{TM}}$ TAM1; Active Motif). The competent cells were grown on MacConkey agar plates (Sigma-Aldrich, UK) with ampicillin $(100 \mu \mathrm{g} / \mathrm{ml})$ at $37^{\circ} \mathrm{C}$ for $45 \mathrm{~min}$ and colonies with the correct insert size were grown overnight in $4 \mathrm{ml}$ of Luria Bertani (LB) broth (Melford Laboratories Ltd., UK) with ampicillin $(100 \mu \mathrm{g} / \mathrm{ml})$ in a shaking incubator at $37^{\circ} \mathrm{C}$. Plasmid DNA purification was performed using a QIAprep®spin DNA miniprep kit (QIAGEN, UK) according to the manufacturer's instructions and purified plasmids were then sent to be sequenced by Eurofins MWG Operon. Protein sequences were then aligned with MAFFT v7 [21].

For the phylogenetic tree, protein sequences from other species were predicted from the ENSEMBL (http://www.ensembl.org/index.html) or NCBI websites (http://www.ncbi.nlm.nih.gov/) and verified in UniProt (http://www.uniprot.org/blast/). Agmatine ureohydrolase or agmatinase was used as the outgroup for the phylogenetic tree as it is an important evolutionary related enzyme also involved in arginine and proline metabolism [2]. The software BioEdit [22] was used to align all protein sequences from different species and generate a file for the Guidance2 server [23-25], where sequence alignment was performed using Fast Fourier Transform, MAFFT v7 [21], as an algorithm for Multiple Sequence Alignment (MSA) with a final score of 0.92 from the original alignment and a statistical confidence cut-off score of 0.93 after the removal of unreliable columns [26]. A final resulting alignment of 239 amino acids was uploaded to MEGA v6 software [27] to predict the best-fitting amino acid substitution model which was the LG [28] and Gamma site heterogeneity model for arginase with the smallest Akaike information criterion (AIC) of 5177.901 and the lowest Bayesian information criterion (BIC) of 5591.264. Bayesian phylogenetic analysis was performed using Bayesian Evolutionary Analysis, by means of the Sampling Trees (BEAST) software package v1.7 [29] employing the best-fitting substitution model $(\mathrm{LG}+\mathrm{G})$, an uncorrelated lognormal relaxed clock model [30], a Yule speciation process, and a Unweighted Pair Group Method with Arithmetic Mean (UPGMA) starting tree. Two runs of BEAST were performed, each with a Markov chain Monte Carlo (MCMC) algorithm of $10,000,000$ generations for Bayesian phylogenetic inference. Bayesian 
Evolutionary Analysis Utility (BEAUti), Tracer v1.6 (http://beast.bio.ed.ac.uk/tracer) [31], LogCombiner (http://beast.bio.ed.ac.uk/logcombiner) with $10 \%$ of burn-in, TreeAnnotator (http://beast.bio.ed.ac.uk/treeannotator) and FigTree (http://beast.bio.ed.ac.uk/figtree) were used to construct the phylogenetic tree. The software MatGAT (Matrix Global Alignment Tool) was used to predict amino acid identity/ similarity between sequences using the BLOcks amino acid SUbstitution 62 (BLOSUM62) Matrix [32]. The exon-intron structures of arginase genes were determined in Salmobase for $S$. salar, ENSEMBL for Danio rerio and Homo sapiens, and by aligning the mRNAs with the corresponding genomic DNA using Splign (https://www.ncbi.nlm.nih.gov/sutils/splign/splign.cgi) for Esox lucius and O. mykiss [33]. The exception was for $\arg 2 b$ in $O$. mykiss where the exons had to be inferred using the genomic sequence for $O$. mykiss arg2a (accession number CCAF010119897.1) as it had the highest query cover (99\%) allowed for alignment in Splign (58\% identity) and hence only exon phase could be determined and not intron size. $100 \%$ identity of arg $2 b$ in O. mykiss matched the accession number CCAF010123604.1, supporting the presence of this gene in contig 23604. The synteny of the arginase loci was analysed in Salmobase using BLAST search (tBLASTn).

\subsection{Fish maintenance and rearing condition}

Apparent healthy rainbow trout with no history of infection were purchased from the Mill of Elrich Trout Fishery (Aberdeenshire, Scotland, UK) and maintained in 1-m-diameter fibreglass tanks with recirculating freshwater at $14+1^{\circ} \mathrm{C}$ at the Scottish fish immunology research centre, the University of Aberdeen, UK. The fish were acclimatised to the system for two weeks prior to use and were fed twice daily with a commercial diet (EWOS) at $2 \%$ body weight/day.

Apparently healthy Atlantic salmon were held as presmolts and smolted at the Ellis aquarium facility at the Marine Scotland Science Marine Laboratory, UK, in tanks containing 3501 of 34-35 ppt seawater with a flow-through of $180 \mathrm{l} / \mathrm{h}$. The fish were acclimatized to $12^{\circ} \mathrm{C}$ for two weeks prior to challenge, and fed daily with Skretting Atlantic Smolt diet at $1 \%$ body weight/day.

\subsection{Constitutive expression of rainbow trout arginase isoforms in tissues}

Six rainbow trout (average weight, $142 \mathrm{~g}$ ) were anaesthetised using 2-phenoxyethanol (Sigma-Aldrich, UK), killed and 17 tissues (tail fin, adipose fin, gills, thymus, brain, scales, skin, muscle, adipose tissue, liver, spleen, gonad, head kidney, posterior kidney, intestine, 
heart and blood) were collected. RNA extraction and complementary (c) DNA synthesis was as described previously $[19,20]$.

\subsection{Modulation of rainbow trout arginase isoform expression in macrophages}

Head kidney macrophages were prepared from four individual fish as described previously $[34,35]$. At day 4 the primary macrophages were stimulated with polyinosinic:polycytidylic acid (polyI:C, $50 \mu \mathrm{g} / \mathrm{ml}$, Sigma-Aldrich, UK), peptidoglycan (PGN, $5 \mu \mathrm{g} / \mathrm{ml}$, Invivogen), trout recombinant (r) Il-1 $\beta$ (20 ng/ml, [36]), rIfn- $\gamma(20 \mathrm{ng} / \mathrm{ml}$, [37]), rIl-6 (100 ng/ml, [34]), rTnf- $\alpha$ (isoform 3) (10 ng/ml, [38]), rIl-12A (p35a1/p40c, $1 \mu \mathrm{l} / \mathrm{ml}$, [39]), rIl-12B (p35a1/p40b1, $1 \mu \mathrm{l} / \mathrm{ml}$, [39]), rll-4/13A and rll-4/13B (200 ng/ml, [18] for 4, 8 and $24 \mathrm{~h}$ ). The rTnf- $\alpha$ (isoform 3), rll-12A and rll-12B were produced in Chinese hamster ovary (CHO) cells. The concentration chosen for each stimulant was deemed optimal from previous studies. RNA extraction and real time RT-PCR analysis of gene expression in head kidney macrophages was conducted as described below.

2.5 Expression of rainbow trout arginase isoforms during $Y$. ruckeri vaccination and challenge

Enteric redmouth disease (ERM) caused by Yersinia ruckeri is responsible for significant economic losses in salmonid aquaculture worldwide but can be prevented by vaccination [40]. The modulated expression of trout arginase paralogues in vivo was first examined in response to vaccination using a commercial ERM vaccine (AQUAVAC® ERM, MSD Animal Health, UK). A group of 24 fish (approximately 50 g) were vaccinated by intraperitoneal (i.p.) injection of $0.1 \mathrm{ml}$ of vaccine, following the manufacturer's instructions. The same number of fish was injected with phosphate buffer saline (PBS) as control. Fish handling and experimental protocols complied with the Guidelines of the European Union Council (2010/63/EU) for the use of laboratory animals, and were carried out under UK Home Office project licence PPL 60/4013, approved by the ethics committee at the University of Aberdeen. Six fish from both the vaccinated and control groups were killed at 1, 3, 7 and 14 days post vaccination. Spleen and gills were taken from each fish and homogenised separately in TRI Reagent ${ }^{\circledR}$ (Sigma-Aldrich, UK). RNA extraction and cDNA synthesis was as described previously [41] and samples were stored at $-20^{\circ} \mathrm{C}$ ready for real time RT-PCR analysis as described below.

We next studied the expression of the arginase paralogues following pathogen challenge of vaccinated and control fish and the challenge procedure and tissue sampling was as described 
previously [41] but with some modifications. Briefly, 32 rainbow trout were vaccinated with AQUAVAC® ERM as above and an additional 32 trout were i.p. injected with $0.1 \mathrm{ml}$ of Hanks' Balanced Salt Solution (HBSS, Sigma-Aldrich, UK) as controls. Ten weeks later, the fish were challenged by i.p. injection with $Y$. ruckeri strain MT3072 at $0.5 \mathrm{ml} /$ fish $\left(1 \times 10^{6}\right.$ $\mathrm{cfu} / \mathrm{ml}$ ) or $0.5 \mathrm{ml}$ of HBSS as control. The fish were sampled at day 1 and day 2, before naïve fish show signs of disease (day 3) under the same challenge dose. Four fish from each group were killed at each sampling point, with gills, head kidney and spleen collected from each fish, and homogenised in TRI Reagent ${ }^{\circledR}$ (Sigma-Aldrich, UK). RNA extraction and cDNA synthesis was as described previously [41] and samples were stored at $-20^{\circ} \mathrm{C}$ ready for real time RT-PCR analysis as described below.

\subsection{Expression of Atlantic salmon arginase isoforms during $P$. perurans infection}

Amoebic gill disease (AGD) is an ectoparasitic infection caused by the amoeba $P$. perurans. A polyclonal and a derived clonal amoebae line, named B8, recently characterized by [42] were cultured and counted as described previously [12] to reach a concentration of 500 cells/l and 5,000 cells/l for an in vivo challenge. Two groups of 5 fish (ca. $400 \mathrm{~g}$ ) were exposed to the two doses of amoebae as described previously [12], in a total volume of 1201 of seawater. Five control fish were exposed to the medium used for amoeba culture. After $4 \mathrm{~h}$ the water volume was increased to 3501 and exchanged in a flow through system at $31 / \mathrm{min}$. At 3 weeks post-exposure, fish were anaesthetised with $0.3 \mathrm{~g} / 1$ of ethyl 3-aminobenzoate methanesulfonate (Sigma-Aldrich, UK) and killed. RNA extraction and cDNA synthesis was as described previously [12]. Real-time RT-PCR analysis was conducted as described below.

\subsection{Expression of rainbow trout arginase isoforms during $T$. bryosalmonae infection}

Proliferative Kidney Disease (PKD) is a parasitic disease caused by the myxozoan parasite $T$. bryosalmonae. Approximately $100 \mathrm{mg}$ of posterior kidney tissue was removed from the area associated with the onset of clinical disease in fish during a natural outbreak at a commercial trout farm in Southern England. T. bryosalmonae presence was confirmed as published previously [11] and kidney swabs from infected and uninfected fish taken at the time of sampling were negative for the presence of common bacterial pathogens, implying the host gene expression profiles seen were as a consequence of the T. bryosalmonae infection. A kidney swelling grade from 0 (control fish) to 3 (higher swelling grade) was assigned to each fish according to the kidney swelling index previously published [43]. RNA extraction and cDNA synthesis was as described previously [11] and real-time RT-PCR analysis was conducted as described below. 


\subsection{Real time RT-PCR}

Real time RT-PCR was carried out using a 384 LightCycler® 480 (Roche Applied Science) in a $10 \mu 1$ reaction using SYBR ${ }^{\circledR}$ Green I (Invitrogen ${ }^{\mathrm{TM}}$, Carlsbad, USA) and IMMOLASE TM DNA Polymerase (Bioline, UK). $4 \mu \mathrm{l}$ cDNA were used in each reaction and the real time analysis program consisted of 1 cycle of denaturation $\left(95^{\circ} \mathrm{C}\right.$ for $\left.10 \mathrm{~min}\right), 40$ cycles of amplification $\left(95^{\circ} \mathrm{C}\right.$ for $30 \mathrm{~s}, 66^{\circ} \mathrm{C}$ for $20 \mathrm{~s}, 72^{\circ} \mathrm{C}$ for $20 \mathrm{~s}, 86^{\circ} \mathrm{C}$ for $\left.5 \mathrm{~s}\right)$, followed by $95^{\circ} \mathrm{C}$ for $5 \mathrm{~s}$ and $75^{\circ} \mathrm{C}$ for $1 \mathrm{~min}$. Program profiles differed for annealing temperature and time for elongation (Tables 1 \& 2). At least one of each real time RT-PCR primer pair was designed to cross an exon-intron boundary to avoid amplification of genomic (g) DNA (Tables $1 \& 2$ ). Primer efficiency was tested using 4 fold serial dilutions of cDNA from pooled RNA samples and calculated by the 'LightCycler ${ }^{\circledR} 480$ software version 1.5.1.62' (Roche Applied Science) as $E=10^{(-1 / s)}$, where $s$ is the slope generated from the Log dilution of cDNA plotted against $\mathrm{Cp}$ (cycle number of crossing point) [44].

\subsection{Statistical analysis}

Normality of data was tested with a Shapiro-Wilk's W-Test (R software, v3.0.1), and data not normally distributed $(\mathrm{p}<0.05)$ were Log transformed. Different tests have been used for the homogeneity of variances $(p>0.05)$ based on the type of data: Bartlett's test was used if the data were normally distributed, Levene's test was used in the case of small departures from normality as it is more robust than Bartlett's test, and the Fligner-Killeen test was used as a non-parametric test which is very robust against departures from normality ( $\mathrm{R}$ software, v3.0.1). To test for transcript constitutive expression in tissues, modulation in rainbow trout macrophages, expression kinetics following $Y$. ruckeri vaccination and infection, and $T$. bryosalmonae infection experiments either a factorial anova (aov) or a linear model ( $\mathrm{lm}$ ) was used, the latter in the case of missing data, with a stepwise deletion method to simplify models using the R software v3.0.1 [45]. Briefly, the most similar parameter estimates were aggregated together in a stepwise a posteriori procedure to combine non-significant factor levels. For multiple comparisons the Holm-Bonferroni correction method [46] was used. Expression levels of the gene of interest (GOI) in the AGD experiment were analysed as reported previously [12]. Briefly, the expression level of the GOI relative to that of the reference gene elongation factor $1 \alpha(e f l \alpha)$ was calculated by the 'Relative expression software tool' (RESTC) [44, 47]. 


\section{Results}

281

282

283

284

285

286

287

288

289

290

291

292

293

294

295

296

297

298

299

300

301

302

303

304

305

306

307

308

309

310

311

312

\subsection{Cloning and sequence analysis}

Four rainbow trout arginase cDNA sequences (accession numbers KX998965 for Arginase 1a, KX998966 for Arginase 1b, KX998967 for Arginase 2a and KX998968 for Arginase 2b) have been cloned and sequence analysed. Each cDNA sequence had an in frame stop codon before the main open reading frame (ORF), a complete ORF and a partial 3'-UTR. The main ORF encoded 338 amino acids (aa), 337 aa, 347 aa and 347 aa for Arginase 1a, 1b, 2a and 2b, respectively (see Suppl. Figures S1-S4). Using the trout arginase protein sequence as bait, the Atlantic salmon counterparts were identified in Salmobase. The salmonid orthologues between trout and salmon share higher identities of 95.9\%, 97.9\%, 96.0\% and $97.7 \%$ for Arginase 1a, 1b, $2 \mathrm{a}$ and $2 \mathrm{~b}$, respectively, than paralogues, i.e. 93.2-93.8\% identities between Arginase $1 \mathrm{a}$ and $1 \mathrm{~b}$, and 93.7-95.4\% identities between $2 \mathrm{a}$ and $2 \mathrm{~b}$ (Table 3 ). The salmonid arginase type I paralogues have lower identities (51.9-53.4\%) to salmonid arginase type II paralogues, similar to those to arginase type II from third round (3R) whole genome duplication (WGD) event fish species (eg. E. lucius, D. rerio, Takifugu rubripes and Oreochromis niloticus, 50.6-53.8\% identities) and tetrapods (52.8-55.1\% identities) (Table 3). As expected, salmonid arginase type I paralogues shared the highest identities to northern pike (E. lucius) Arginase 1 (87.9-91.4\%), high identities to 3R fish Arginase 1 (67.5-77.1\%), medium identities to 2R spotted gar (Lepisosteus oculatus) Arginase 1 (62.8-63.3\%), and lowest identities to tetrapod arginase type I (57.2-60.2\%) (Table 3). Similarly, salmonid arginase type II paralogues share the highest identities to northern pike Arginase 2 (88.590.2\%), have relatively high identities to other 3R fish arginase type II (73.0-81.0\%), medium identities to $2 \mathrm{R}$ spotted gar arginase type II (64.3-65.5\%), and lowest identities to tetrapod arginase type II (61.7-64.1\%) (Table 3).

The amino acid sequences were further studied by phylogenetic analysis (Suppl. Figure S5) using the BEAST software package v1.7. [29]. Arginase type I and II are clearly two independent clades. Within both the arginase type I and II clades, the ray-finned fish (Actinopterygii) molecules group together to form a sub-clade separate from the tetrapod and lobe-finned fish (coelacanths) species. In the subclades containing arginase sequences from salmonids and pike, their closest $3 \mathrm{R}$ relative, the salmonid orthologues group first, a typical scenario where the two paralogues have risen from the 4R WGD in salmonids. Furthermore, the duplicated salmonid paralogues are located on different chromosomes (in Atlantic salmon, Figure 1) or contigs (in rainbow trout) (Figure 2). Although syntenic analysis is not 
possible in rainbow trout because of short contig length, syntenic conservation in the paralogue loci was apparent in Atlantic salmon (Figure 1). Such evidence suggests that the salmonid arginase paralogues are the result of the Ss4R duplication event. Interestingly, in the coelacanth (Latimeria chalumnae), Carolina anole (Anolis carolinensis - class Reptilia), and collared flycatcher (Ficedula albicollis - class Aves) only a type II sequence was found.

All the salmonid arginase genes have an 8 exon/ 7 intron structure, with highly conserved exon length although some variability is seen for the first and last exon. The introns are more variable in size but have a conserved intron phase (Figure 2). Conserved exon length is also present in the other fish and the human genes, although the latter has a different length for the third exon in both arginase I and II (Figure 2).

\subsection{Constitutive expression of rainbow trout arginase isoforms in tissues}

The constitutive expression of the four arginase isoforms was studied in 17 different tissues from healthy rainbow trout by real time RT-PCR (Figure 3). Statistical analysis was performed for each gene among the different tissues, starting with a general aov model ( $\mathrm{R}$ software, v3.0.1), and then grouping together the most similar parameter estimates in a stepwise a posteriori procedure to combine non-significant factor levels until the models' comparison was significant $(\mathrm{p}<0.05)$. Diagnostic plots of the final model were always performed to validate that linear model assumptions were met (results not shown). The final model of argla analysis showed that the tissues grouped based on their expression as follows, from lowest to highest: 1) intestine; 2) adipose tissue, spleen, blood, head kidney, scales and tail fin; 3) adipose fin, brain, heart, gonad, muscle and thymus; 4) skin; 5) gills and liver; 6) posterior kidney. For $\arg 1 b$ the groups were: 1) tail fin, intestine and scales; 2) adipose tissue, spleen and head kidney; 3) adipose fin and posterior kidney; 4) blood, muscle and thymus; 5) gills; 6) brain, skin, heart, gonad and liver. For $\arg 2 a$ the tissues were grouped as: 1) liver; 2) tail fin; 3) adipose tissue, intestine, posterior kidney, head kidney, heart and skin; 4) blood, gonad, scales, gills, spleen, brain and thymus; 5) adipose fin and muscle. Lastly, for $\arg 2 b$ the groups were: 1) liver; 2) intestine and tail fin; 3) adipose tissue, spleen, gills and scales; 4) adipose fin, skin, blood, posterior kidney, gonad, head kidney and thymus; 5) heart; 6) brain and muscle. Overall, constitutive expression of one or both paralogues was seen in most tissues. However, $\arg 1 a$ was often higher than $\arg 1 b$, with highest expression seen in the posterior kidney. As in mammals, the expression of type I arginase was much higher in liver in comparison with type II, with almost no expression for $\arg 2 a$ seen in this tissue. 


\subsection{Modulation of arginase isoform expression in rainbow trout macrophages}

Macrophages represent a first line of defence in vivo and they are important for arginase enzyme activity after polarization along the M2 pathway. Therefore, we examined the expression and modulation of rainbow trout arginase isoforms in primary head kidney macrophages stimulated by a viral and bacterial PAMP, namely polyI:C and PGN, and a variety of recombinant (r) trout cytokines (rIl-1 $\beta$, rIl-6, rIfn- $\gamma$, rIl-12A, rIl-12B, rTnf- $\alpha$, rIl4/13A, and rIl-4/13B). A separate linear model ( $\mathrm{lm}$ ) was used for the analysis of each gene and time point (R software, v3.0.1). The expression of argla was more highly induced in comparison to the other isoforms, while $\arg 1 b$ was the least inducible. $\operatorname{argla}$ was mainly found up regulated in comparison to control fish at $24 \mathrm{~h}$ after stimulation with polyI:C (28fold, $\mathrm{p}<0.001, \mathrm{n}=4$ ), PGN (66-fold, $\mathrm{p}<0.001, \mathrm{n}=4$ ), rIl-1 $\beta$ (45-fold, $\mathrm{p}<0.001, \mathrm{n}=3$ ), rIl6 (3-fold, $\mathrm{p}<0.01, \mathrm{n}=3$ ), and rTnf- $\alpha$ (isoform 3) (16-fold, $\mathrm{p}<0.001, \mathrm{n}=4$ ). The expression of argla and $\arg 1 b$ was also found to be significantly down regulated in comparison to control fish in three cases: $\arg 1 a$ after stimulation with rIl-4/13A at $8 \mathrm{~h}(\mathrm{p}<0.05, \mathrm{n}=3)$ and rIfn- $\gamma$ at $24 \mathrm{~h}(\mathrm{p}<0.001, \mathrm{n}=3)$ and $\arg 1 b$ after stimulation with rIl-4/13A at $24 \mathrm{~h}(\mathrm{p}<0.01$, $\mathrm{n}=3$ ). $\arg 2 a$ was mostly induced at $4 \mathrm{~h}$ by the different stimulants in comparison to $\arg 2 b$ but both isoforms were induced significantly by rIl-4/13A in comparison to control fish: $\arg 2 a$ at $4 \mathrm{~h}(2$-fold, $\mathrm{p}<0.05, \mathrm{n}=3)$ and $\arg 2 b$ at all three timings (2-fold, $\mathrm{p}<0.01, \mathrm{n}=3$, at 4 and $8 \mathrm{~h}$; 2-fold, $\mathrm{p}<0.05, \mathrm{n}=4$, at $24 \mathrm{~h}$ ).

\subsection{Expression of rainbow trout arginase isoforms during $Y$. ruckeri vaccination and challenge}

The expression of all trout arginase genes except argla in gills was modulated in the spleen and gills by ERM injection vaccination (Figure 5). In the spleen, argla expression was increased 6.9-fold at 1 day post vaccination (dpv) and increased further to 50.9-fold at $3 \mathrm{dpv}$ but had come back to control levels at 7 and $14 \mathrm{dpv}$. $\arg 2 b$ expression was also relatively highly induced (11.3-fold at $1 \mathrm{dpv}$ and 2.9-fold at $3 \mathrm{dpv}$ ). A modest up regulation by ERM vaccination was also seen at $1 \mathrm{dpv}$ for $\arg 1 b$ and $\arg 2 a$ (about 4-fold) but $\arg 2 a$ expression subsequently decreased to 0.42 -fold of the time matched control at $7 \mathrm{dpv}$ (Figure 5). Although $\arg 1 \mathrm{a}$ expression was refractory in the gills, a modest increase (up to 2-fold) was seen after vaccination at $1-14 \mathrm{dpv}$ for $\arg 1 b$, and at 1,3 and $14 \mathrm{dpv}$ for $\arg 2 \mathrm{a}$ and $\arg 2 b$ (Figure 5). 
We next investigated trout arginase gene expression after challenge with $Y$. ruckeri in ERM vaccinated and control fish. Appropriate control groups (unvaccinated fish - HBSS_V; nonchallenged fish - HBSS_C) were included in the analysis. Expression of the four isoforms was studied in the gills, spleen and head kidney at days 1 and 2 post challenge. For statistical analysis, linear models $(\mathrm{lm})$ for each gene, time point, and tissue were applied within $\mathrm{R}$ software, v3.0.1, and for multiple comparisons the Holm-Bonferroni correction method [46] was used. In comparison to control fish (HBSS_V - HBSS_C), in unvaccinated fish challenged with $Y$. ruckeri (HBSS_V - YR_C) argla was more highly induced than arglb and was up regulated mainly in spleen and head kidney at days 1 and $2(\mathrm{p}<0.001, \mathrm{n}=4)$. Almost no up regulation was found in head kidney for $\arg 1 b$ and $\arg 2 a$, with only a small increase in $\arg 1 b$ at day $1(\mathrm{p}<0.05, \mathrm{n}=4)$. Significant up regulation was also found in spleen for $\arg 1 b$ at day $2(\mathrm{p}<0.001, \mathrm{n}=4)$. In contrast, the type II arginase isoforms showed highest induction in gills after challenge with $Y$. ruckeri, as seen with $\arg 2 a$ in both vaccinated and unvaccinated fish at day $1(\mathrm{p}<0.001, \mathrm{n}=4)$, and with $\arg 2 b$ in unvaccinated fish at day $2(\mathrm{p}<0.001, \mathrm{n}=4)$. However, up regulation of the arginase II isoforms was also seen in the spleen of unvaccinated fish challenged with Y. ruckeri (HBSS_V - YR_C) in comparison to control fish (HBSS_V - HBSS_C) at both days, for $\arg 2 a$ at day 1 (p $<0.001$, $\mathrm{n}=4)$ and day $2(\mathrm{p}<0.01, \mathrm{n}=4)$ and for $\arg 2 b$ at both days $(\mathrm{p}<0.001, \mathrm{n}=4)$, with a low level of induction in head kidney for $\arg 2 b$. Curiously, injection of $Y$. ruckeri vaccinated fish with HBSS (YR_V - HBSS_C) caused a significant down regulation of 1) argla at day 1 in spleen $(\mathrm{p}<0.01, \mathrm{n}=4)$ and head kidney $(\mathrm{p}<0.001, \mathrm{n}=4) ; 2) \arg 2 a$ at day 1 in spleen $(\mathrm{p}<$ $0.05, \mathrm{n}=4)$; and 3$) \arg 2 b$ at day 1 in head kidney $(\mathrm{p}<0.001, \mathrm{n}=4)$. Significant up regulation of vaccinated fish challenged with $Y$. ruckeri (YR_V - YR_C) was found only at day 1 in spleen $(\mathrm{p}<0.01, \mathrm{n}=4)$ and head kidney $(\mathrm{p}<0.001, \mathrm{n}=4)$ for $\arg 1 a$; in gills $(\mathrm{p}<$ $0.001, \mathrm{n}=4)$ for $\arg 2 a$; and in gills $(\mathrm{p}<0.05, \mathrm{n}=4)$, spleen $(\mathrm{p}<0.05, \mathrm{n}=4)$ and head kidney ( $\mathrm{p}<0.001, \mathrm{n}=4)$ for $\arg 2 b$.

\subsection{Expression of arginase isoforms during parasitic infection}

The expression of Atlantic salmon arginase transcripts was examined during $P$. perurans (AGD) infection. $\operatorname{argla}$, $\arg 1 b, \arg 2 a$ were significantly down regulated in comparison to control fish in gills from salmon exposed to both concentrations of cloned B8 trophozoites. argla and $\arg 1 b$ were also down regulated when using the higher concentration $(5,000$ cells/l) of the polyclonal culture. In contrast, $\arg 2 b$ was significantly up regulated by exposure to the higher concentration of the clonal culture $(p<0.05, n=5)$. Similar results 
were found for the expression of rainbow trout $\operatorname{argla}$ and $\arg 1 b$ transcripts during $T$. bryosalmonae (PKD) infection, where the transcripts in kidney were down regulated with increasing swelling index. The type II arginases were not modulated by the presence of the parasite.

\section{Discussion}

Arginase, a ubiquitous enzyme found in prokaryotic and eukaryotic organisms, is responsible for cleaving the guanidine group from arginine into ornithine and urea [1,2]. Invertebrates have only one type of arginase, localized in mitochondria, while most vertebrates have two types as a consequence of a gene duplication that occurred after the separation of vertebrates and invertebrates $[2,3]$. These two arginase genes have diverged in terms of where and when they are expressed. For example, type I arginase is cytoplasmic and expressed in liver as part of the urea cycle whilst type II is a mitochondrial enzyme, likely the surviving form of the ancestral gene, and is expressed in a variety of peripheral tissues [4]. Similarly within the immune system the roles of these two isoforms differ, as seen in mammalian macrophages which can express both types [48]. Classically type I arginase is expressed in M2 macrophages, associated with anti-inflammatory responses and wound healing. In contrast type II plays a role in pro-inflammatory responses of macrophages and is expressed upon activation of M1 cells by LPS, during monocyte maturation to macrophages and in some chronic disease states [49]. It is not clear that the above mammalian paradigm will hold true in all vertebrate groups that express these two arginase isoforms, and indeed in fish there is evidence to suggest that type II may be a good marker of M2 macrophages in carp [5-8]. In salmonid fish, that have undergone a further round of WGD (Ss4R), the situation may be even more complex with the potential for further paralogues of arginase to be present. Hence this study initially characterised the arginase genes found in trout and salmon, and then examined their constitutive expression in a range of tissues, and after immune stimulation in vitro and in vivo, to assess whether there was evidence of functional divergence between the

Our bioinformatics analysis revealed that four different arginase isoforms are present in rainbow trout and Atlantic salmon, two related to type I ( $\arg 1 a, \arg 1 b)$ and two related to type II ( $\arg 2 a, \arg 2 b)$ arginase, as evidenced by the amino acid homology analysis (Table 3 ) and phylogenetic analysis (Suppl. Figure S5). In the phylogenetic tree type I and II molecules 
to form a sub-clade separate from lobe-finned fish and tetrapods. Interestingly only a single type of arginase, type II, appears present in the coelacanth (L. chalumnae), lizards ( $A$. carolinensis) and birds (F. albicollis), with gene loss of type I in the latter (reptiles and birds) hypothesised to be linked to the transition to land and a further adaptation to dispose the excess of ammonium nitrogen into uric acid (uricotelic) $[1,50]$. Occurrence of the duplicated genes in salmonids is most likely a result of the known ancestral WGD event that occurred in this fish lineage, as suggested by the homology and gene synteny analysis (Table 3, Figure 1) [13].

451

452

Constitutive expression of the four arginase isoforms was next studied in 17 different tissues from healthy rainbow trout. The findings demonstrated that in general one or both paralogues of type I and type II arginase were expressed in most tissues. However, argla was often higher than $\arg 1 b$, with highest expression seen in the posterior kidney. Interestingly, both type I paralogues were much more highly expressed in liver compared with the type II paralogues, with almost no expression of $\arg 2 a$ apparent. Similarly, in mammals arginase type I is mainly expressed in liver where it is involved in the hepatic urea cycle [4].

Macrophages represent an important innate defence against various pathogens, and in addition to undergoing phagocytosis, bacterial killing, and defence against protozoan and metazoan parasites, they aid wound healing [2]. Two main types of macrophage populations are known that differ in terms of activation triggers and effector function: 1) the classically activated M1 macrophages induced by Th1 cytokines that convert L-arginine to L-citrulline, producing NO and reactive nitrogen species, and 2) the alternatively activated M2 macrophages that express arginase after activation with Th2 cytokines [4, 8]. Recently this polarisation model has been considered an oversimplification in mammals, and the M2 macrophages can now be subdivided into: i) M2a macrophages activated by IL-4 or IL-13, ii) $\mathrm{M} 2 \mathrm{~b}$ macrophages induced by the combined exposure to immune complexes and toll-like receptor (TLR) or IL-1R agonists, and iii) M2c macrophages deactivated by glucocorticoids or by cytokines such as transforming growth factor (TGF)- $\beta$ or IL-10 [5, 51, 52]. Both types of activated macrophages (M1 and M2) have been demonstrated in fish, with the latter showing elevated levels of arginase activity [5-8]. In this study we examined the expression and modulation of rainbow trout arginase isoforms in primary head kidney macrophages stimulated by two PAMPs (polyI:C, PGN) and a range of trout cytokines relevant to proinflammatory responses and type-I and -II immunity (e.g. rIl-1 $\beta$, rIl-4/13A, rIl-4/13B, rIl- 
6, rI-12A, rIl-12B, rIfn- $\gamma$, rTnf- $\alpha$ - isoform 3). The expression of $\arg 1 a$ was much more highly induced in comparison to the other isoforms, with $\arg 1 b$ the least inducible. Moreover, the highest transcript levels of $\arg 1 a$ were seen at $24 \mathrm{~h}$ after stimulation (with polyI:C, PGN, rIl-1 $\beta$, rIl-6 and rTnf- $\alpha$ ), although a degree of up regulation was also apparent at $8 \mathrm{~h}$. Interestingly, argla and $\arg 1 b$ were significantly down regulated after stimulation with rIl4/13A (at $8 \mathrm{~h}$ for $\operatorname{argla}$ and $24 \mathrm{~h}$ for $\arg 1 b$ ). The two type II arginases differed in their kinetics of induction with $\arg 2 a$ being up regulated at $4 \mathrm{~h}$ by a range of stimulants in comparison to $\arg 2 b$ but both isoforms were significantly induced by rIl-4/13A ( $\arg 2 a$ at $4 \mathrm{~h}$, $\arg 2 b$ at $4 \mathrm{~h}, 8 \mathrm{~h}$ and $12 \mathrm{~h}$ ). These results hint that in relation to trout macrophage expression type I arginase may play a role in pro inflammatory responses (M1) whilst type II appears induced by type II cytokines (i.e. Il-4/13) and is potentially a marker of M2 cells (M2a) as in carp [5].

We next studied the expression of the arginase isoforms in vivo in trout after vaccination and/ or challenge with $Y$. ruckeri, the causative agent of enteric redmouth disease (ERM) in salmonid fish species, and in trout and salmon after parasitic infection. In the vaccination experiment, the trout arginase isoforms were more highly induced at the systemic level in spleen, at day 1 (all isoforms) and day 3 ( $\arg 1 a, \arg 2 b)$, than in the mucosal tissue studied. Interestingly $\operatorname{argla}$ showed the highest up regulation in spleen and was not modulated in gills, in contrast to the other isoforms, showing a predominant expression in the spleen but were also up regulated in the gills. In the vaccination/ challenge experiment, the different isoforms also had different expression profiles in trout after infection, in terms of tissue, level and kinetics of expression. The argla transcript was more highly induced by $Y$. ruckeri than arglb in unvaccinated fish and up regulation of these paralogues was highest in the spleen, especially at day 2 . In contrast $\arg 2 a$ and $\arg 2 b$ showed highest up regulation in the gills of challenged/ unvaccinated fish, with $\arg 2 a$ induction highest at day 1 but $\arg 2 b$ at day 2 . As seen with pro-inflammatory gene expression in this host-pathogen model [41], vaccinated fish exposed to $Y$. ruckeri typically showed lower induction levels of the arginase isoforms in comparison to the challenged/ unvaccinated fish. The results to live vs dead ERM also differed, as seen in the first few days post-vaccination or challenge (of unvaccinated fish). The most obvious differences were the later peak in $\arg 1 \mathrm{~b}$ expression in spleen, and the more pronounced (relative to the spleen response) increases of $\arg 2 a / b$ in the gills following challenge. Clearly the isoforms have diverged in their tissue expression pattern when comparing type I and type II genes, and also in their level of induction (as seen with the type 
508

509

510

511

512

513

514

515

516

517

518

519

520

521

522

523

524

525

526

527

528

529

530

531

532

533

534

535

536

537

538

539

I paralogues) and kinetics of induction (as seen with the type II paralogues), similar to the in vitro findings above.

Two parasite infection models were also studied: AGD in the gills of Atlantic salmon and PKD in the kidney of trout. During AGD $\arg 1 a$, $\arg 1 b$ and $\arg 2 a$ were significantly down regulated in gill tissue in comparison to control fish, although with $\arg 1 a$ and $\arg 1 b$ only at the higher concentration of trophozoites in the case of the polyclonal culture used for infection and with $\arg 2 a$ only using the clonal B8 culture, considered a relatively virulent clone [42]. The down regulation of arginase type I was as seen previously [12]. Curiously, $\arg 2 b$ was significantly up regulated with the higher concentration of trophozoites for this clone. Similar results were found for PKD in trout. argla and $\arg 1 b$ were down regulated in kidneys with the highest swelling index (grade 3), with a clear correlation to increasing pathology in the case of $\arg 1 \mathrm{la}$. This is in line with a previous study of arginase type I, where the primers used amplified both paralogues [11]. However, the two arginase type II paralogues were not modulated by the presence of the parasite. In a previous study, $i l-4 / 13 A$ and $i l-4 / 13 B 2$, believed to be related to the Th2 pathway in fish (M2a type) $[18,53,54]$ were significantly up regulated during AGD [12]. Whether this accounts for the increase in $\arg 2 b$ transcript levels during AGD and whether this is beneficial to the host or to P. perurans remains to be determined. However, once again it is clear that differences exist between the type I and type II arginase expression patterns, in this case after parasite infection, with arg I and arg2 expression potentially induced by different stimuli as in the trypanosome-carp model [7].

In summary, four arginase isoforms have been characterised in trout and salmon. Analysis of their constitutive and modulated expression has shown that the type I and II genes have different responses and that the paralogues also vary in their magnitude and kinetics of expression. The data support the contention that arginase type II may be a more relevant marker of M2a cells in teleost fish, with arginase type I induced by proinflammatory stimuli and down regulated during parasite infections. However, in salmonids there is an added complexity with the presence of additional paralogues which also show varied expression patterns.

\section{Ethics statement}

All handling of fish was conducted in accordance with the Animals (Scientific Procedures) Act 1986 and all proposed experiments were first subject to detailed statistical review to 
540 ensure that a minimum number of fish was used, which would allow statistically meaningful 541 results to be obtained.

\section{Acknowledgements}

543 OB was supported by a PhD studentship from the Marine Collaboration Research Forum 544 (MarCRF), which is a collaboration between the University of Aberdeen and Marine

545 Scotland Science, Marine Laboratory (MSS), and through Scottish Government project 546 AQ0080. EW was supported by a PhD studentship from the Ministry of Science and 547 Technology of Thailand and Mahasarakham University. TW received funding from the 548 Marine Alliance for Science and Technology for Scotland (MASTS), a pooling initiative 549 funded by the Scottish Funding Council (grant reference HR09011), and JWH was supported 550 by the Swiss National Science Foundation (grant reference CRSII3_147649-1). 


\section{Figures and Tables}

553 Figure 1. Gene synteny of Atlantic salmon arginase. The synteny was analysed using

554 Salmobase (http://salmobase.org). The syntenically conserved gene blocks are shown in

555 matching colours. The arrows indicate the transcriptional direction.

556 Figure 2. Inferred exon-intron structures of arginase I (A) and arginase II (B). Quantitative 557 information on the lengths of exon coding sequence (black boxes, to scale) and introns (white 558 boxes, not to scale), and intron phase are presented. Inferred exons and intron phase for $\arg 2 b$ 559 in $O$. mykiss were characterised using the $\arg 2 a$ genomic sequence (accession number 560 CCAF010119897.1).

561 Figure 3. Expression profiles of $\arg 1 a, \arg 1 b, \arg 2 a, \arg 2 b$ in 17 different tissues of healthy 562 rainbow trout determined by real-time RT-PCR. Transcript levels were first calculated using 563 a serial dilution of references in the same PCR run. Relative expression levels (mean + SEM, 564 $\mathrm{n}=6$ ) are expressed as arbitrary units after normalisation to efl $\alpha$.

565 Figure 4. Relative expression of rainbow trout $\arg 1 a, \arg 1 b, \arg 2 a, \arg 2 b$ in primary head 566 kidney macrophages following stimulation with PAMPs and cytokines. The fold change 567 (mean $\pm \mathrm{SEM}, \mathrm{n}=4$ ) was calculated as the relative expression in comparison to control cells, 568 after normalizing to efl $\alpha$. A linear model ( $\mathrm{lm}$ ) was used for statistical analysis (R software, 569 v3.0.1). * $=\mathrm{p}<0.05, * *=\mathrm{p}<0.01, * * *=\mathrm{p}<0.001$.

Figure 5. Relative expression of rainbow trout $\arg 1 a, \arg 1 b, \arg 2 a, \arg 2 b$ in spleen and gills after vaccination with AQUAVAC® ERM. Two groups of rainbow trout were vaccinated by i.p. injection of AQUAVAC® ERM or PBS as control, and spleen/gill tissue sampled at day 1, 3, 7 and 14. The fold change (means $\pm \mathrm{SEM}, \mathrm{n}=6$ ) was calculated as the mean expression levels in vaccinated fish normalized to time-matched controls in the same tissue. The relative significance of a LSD post hoc test after a significant one way-ANOVA between the vaccinated and control groups at the same time point is shown above the bars as: $*=p<$ $0.05, * *=\mathrm{p}<0.01$ and $* * *=\mathrm{p}<0.001$.

578 Figure 6. Relative expression of rainbow trout $\arg 1 a, \arg 1 b, \arg 2 a, \arg 2 b$ in gill, spleen, 579 head kidney samples of control (HBSS_V) and ERM vaccinated (YR_V) fish subsequently 580 injected with HBSS (HBSS_C) or Yersinia ruckeri (YR_C) and sampled 1 and 2 days later. 
control fish, normalized to efl $\alpha$. A linear model ( $\mathrm{lm})$ with the Holm-Bonferroni correction method for multiple comparisons were used for statistical analysis ( $\mathrm{R}$ software, v3.0.1). $*=p$ $<0.05, * *=\mathrm{p}<0.01, * * *=\mathrm{p}<0.001$.

Figure 7. Relative expression of Atlantic salmon $\arg 1 a, \arg 1 b, \arg 2 a, \arg 2 b$ (mean $\pm \mathrm{SEM}$, $\mathrm{n}=5$ ) in gill samples infected with a polyclonal or clonal culture of $P$. perurans at two trophozoite doses. Expression was determined using REST@ 2009 (relative expression software tool), and the fold change calculated as the relative expression in comparison to gills from control fish, normalized to efl $\alpha . *=p<0.05, * *=p<0.01, * * *=p<0.001$.

Figure 8. Relative expression of rainbow trout $\arg 1 a, \arg 1 b, \arg 2 a, \arg 2 b$ in kidney samples infected with T. bryosalmonae, presented as a fold change relative to control kidney samples, after normalizing to efl $\alpha$. A kidney swelling grade from 0 (control fish) to 3 (higher swelling grade) was assigned to each fish according to the kidney swelling index of [43]. A linear model ( $\mathrm{lm}$ ) with the Holm-Bonferroni correction method for multiple comparisons were used for statistical analysis (R software, v3.0.1). $*=\mathrm{p}<0.05, * *=\mathrm{p}<0.01, * * *=\mathrm{p}<0.001, \mathrm{n}=$ 10 for uninfected fish; $\mathrm{n}=5$ for fish exhibiting grade $1 ; \mathrm{n}=9$ for fish exhibiting grade from 1 to $2 ; \mathrm{n}=10$ for fish exhibiting grade $2 ; \mathrm{n}=9$ for fish exhibiting grade 3 .

Table 1. Rainbow trout primer sequences used for PCR cloning and expression analysis (real time RT-PCR).

Table 2. Atlantic salmon primer sequences used for gene expression analysis (real time RTPCR).

Table 3. Comparison of the amino acid identities/ similarities for arginase I and II using the Similarity Matrix BLOSUM62 within MatGat 2.02 software. 
1. Jenkinson CP, Grody WW, Cederbaum SD. Comparative properties of arginases. Comparative Biochemistry and Physiology - B Biochemistry and Molecular Biology 1996;114(1):107-32.

2. Dzik JM. Evolutionary roots of arginase expression and regulation. Frontiers in

3. Samson M-. Drosophila arginase is produced from a nonvital gene that contains the elav locus within its third intron. Journal of Biological Chemistry 2000;275(40):31107-14.

4. Munder M. Arginase: An emerging key player in the mammalian immune system: REVIEW. British Journal of Pharmacology 2009;158(3):638-51.

5. Wiegertjes GF, Wentzel AS, Spaink HP, Elks PM, Fink IR. Polarization of immune responses in fish: The 'macrophages first' point of view. Molecular Immunology 2016;69:146-56.

6. Skugor S, Glover KA, Nilsen F, Krasnov A. Local and systemic gene expression responses of Atlantic salmon (Salmo salar L.) to infection with the salmon louse (Lepeophtheirus salmonis). BMC Genomics 2008;9(498):1-18.

7. Joerink M, Forlenza M, Ribeiro CMS, de Vries BJ, Savelkoul HFJ, Wiegertjes GF. Differential macrophage polarisation during parasitic infections in common carp (Cyprinus carpio L.). Fish \& Shellfish Immunology 2006 11;21(5):561-71.

8. Forlenza M, Fink IR, Raes G, Wiegertjes GF. Heterogeneity of macrophage activation in fish. Developmental and Comparative Immunology 2011 12;35(12):1246-55.

9. Joerink M, Savelkoul HFJ, Wiegertjes GF. Evolutionary conservation of alternative activation of macrophages: Structural and functional characterization of arginase 1 and 2 in carp (Cyprinus carpio L.). Molecular Immunology 2006;43(8):1116-28.

10. Joerink M, Ribeiro CMS, Stet RJM, Hermsen T, Savelkoul HFJ, Wiegertjes GF. Head kidney-derived macrophages of common carp (Cyprinus carpio L.) show plasticity and functional polarization upon differential stimulation. Journal of Immunology 2006;177(1):61-9.

11. Gorgoglione B, Wang T, Secombes CJ, Holland JW. Immune gene expression profiling of proliferative kidney disease in rainbow trout Oncorhynchus mykiss reveals a dominance of anti-inflammatory, antibody and $\mathrm{T}$ helper cell-like activities. Veterinary Research 2013;44(55):1-16. 
12. Benedicenti O, Collins C, Wang T, McCarthy U, Secombes CJ. Which th pathway is involved during late stage amoebic gill disease? Fish \& Shellfish Immunology 2015 $10 ; 46(2): 417-25$.

13. Lien S, Koop BF, Sandve SR, Miller JR, Kent MP, Nome T, Hvidsten TR, Leong JS, Minkley DR, Zimin A, Grammes F, Grove H, Gjuvsland A, Walenz B, Hermansen RA, Von Schalburg K, Rondeau EB, Di Genova A, Samy JKA, Olav Vik J, Vigeland MD, Caler L, Grimholt U, Jentoft S, Inge Våge D, De Jong P, Moen T, Baranski M, Palti Y, Smith DR, Yorke JA, Nederbragt AJ, Tooming-Klunderud A, Jakobsen KS, Jiang X, Fan D, Hu Y, Liberles DA, Vidal R, Iturra P, Jones SJM, Jonassen I, Maass A, Omholt SW, Davidson WS. The Atlantic salmon genome provides insights into rediploidization. Nature 2016;533:200-5.

14. Macqueen DJ, Johnston IA. A well-constrained estimate for the timing of the salmonid whole genome duplication reveals major decoupling from species diversification. Proceedings of the Royal Society B: Biological Sciences 2014;281(20132881):1-8.

15. Pasquier J, Cabau C, Nguyen T, Jouanno E, Severac D, Braasch I, Journot L, Pontarotti P, Klopp C, Postlethwait JH, Guiguen Y, Bobe J. Gene evolution and gene expression after whole genome duplication in fish: The PhyloFish database. BMC Genomics $2016 ; 17(1)$.

16. Altschul SF, Gish W, Miller W, Myers EW, Lipman DJ. Basic local alignment search tool. Journal of Molecular Biology 19905 October 1990;215(3):403-10.

17. Wang T, Jiang Y, Wang A, Husain M, Xu Q, Secombes CJ. Identification of the salmonid IL-17A/F1a/b, IL-17A/F2b, IL-17A/F3 and IL-17N genes and analysis of their expression following in vitro stimulation and infection. Immunogenetics 2015;67(7):395-412.

18. Wang T, Johansson P, Abós B, Holt A, Tafalla C, Jiang Y, Wang A, Xu Q, Qi Z, Huang W, Costa MM, Diaz-Rosales P, Holland JW, Secombes CJ. First in-depth analysis of the novel Th2-type cytokines in salmonid fish reveals distinct patterns of expression and modulation but overlapping bioactivities. Oncotarget 2016;7(10):1091746.

19. Jiang Y, Husain M, Qi Z, Bird S, Wang T. Identification and expression analysis of two interleukin-23 $\alpha$ (p19) isoforms, in rainbow trout Oncorhynchus mykiss and Atlantic salmon Salmo salar. Molecular Immunology 2015 8;66(2):216-28.

20. Wang T, Diaz-Rosales P, Costa MM, Campbell S, Snow M, Collet B, Martin SAM, Secombes CJ. Functional characterization of a nonmammalian IL-21: Rainbow trout Oncorhynchus mykiss IL-21 upregulates the expression of the Th cell signature cytokines IFN- $\gamma$, IL-10, and IL-22. Journal of Immunology 2011;186(2):708-21.

21. Katoh K, Standley DM. MAFFT multiple sequence alignment software version 7: Improvements in performance and usability. Molecular Biology and Evolution 2013;30(4):772-80. 
22. Hall TA. Bioedit: A user-friendly biological sequence alignment editor and analysis program for windows 95/98/NT. Nucleic Acids Symposium Series 1999;41:95-8.

23. Landan G, Graur, D. Local reliability measures from sets of co-optimal multiple sequence alignments. Pacific symposium on biocomputing 2008, PSB 2008; 2008. 15-24 p.

24. Sela I, Ashkenazy H, Katoh K, Pupko T. GUIDANCE2: Accurate detection of unreliable alignment regions accounting for the uncertainty of multiple parameters. Nucleic Acids Research 2015;43(W1):W7-W14.

25. Penn O, Privman E, Ashkenazy H, Landan G, Graur D, Pupko T. GUIDANCE: A web server for assessing alignment confidence scores. Nucleic Acids Research 2010;38(SUPPL. 2).

26. Penn O, Privman E, Landan G, Graur D, Pupko T. An alignment confidence score capturing robustness to guide tree uncertainty. Molecular Biology and Evolution 2010;27(8):1759-67.

27. Tamura K, Stecher G, Peterson D, Filipski A, Kumar S. MEGA6: Molecular evolutionary genetics analysis version 6.0. Molecular Biology and Evolution 2013;30(12):2725-9.

28. Le SQ, Gascuel O. An improved general amino acid replacement matrix. Molecular Biology and Evolution 2008;25(7):1307-20.

29. Drummond AJ, Suchard MA, Xie D, Rambaut A. Bayesian phylogenetics with BEAUti and the BEAST 1.7. Molecular Biology and Evolution 2012;29(8):1969-73.

30. Drummond AJ, Ho SYW, Phillips MJ, Rambaut A. Relaxed phylogenetics and dating with confidence. PLoS Biology 2006;4(5):699-710.

31. Rambaut A, Suchard M, Xie D, Drummond A. Tracer v1.6. Http://beast.Bio.Ed.Ac.uk/software/tracer/ 2014.

32. Campanella JJ, Bitincka L, Smalley J. MatGAT: An application that generates similarity/identity matrices using protein or DNA sequences. BMC Bioinformatics 2003;4(29):1-4.

33. Kapustin Y, Souvorov A, Tatusova T, Lipman D. Splign: Algorithms for computing spliced alignments with identification of paralogs. Biology Direct 2008;3(20):1-13.

34. Costa MM, Maehr T, Diaz-Rosales P, Secombes CJ, Wang T. Bioactivity studies of rainbow trout (Oncorhynchus mykiss) interleukin-6: Effects on macrophage growth and antimicrobial peptide gene expression. Molecular Immunology 2011 9;48(15-16):190316.

35. Xu Q, Li R, Monte MM, Jiang Y, Nie P, Holland JW, Secombes CJ, Wang T. Sequence and expression analysis of rainbow trout CXCR2, CXCR3a and CXCR3b aids interpretation of lineage-specific conversion, loss and expansion of these receptors 
during vertebrate evolution. Developmental and Comparative Immunology 2014 $8 ; 45(2): 201-13$.

36. Hong S, Zou J, Crampe M, Peddie S, Scapigliati G, Bols N, Cunningham C, Secombes CJ. The production and bioactivity of rainbow trout (Oncorhynchus mykiss) recombinant IL-1 $\beta$. Veterinary Immunology and Immunopathology 2001 8/30;81(1-2):1-14.

37. Wang T, Huang W, Costa MM, Martin SAM, Secombes CJ. Two copies of the genes encoding the subunits of putative interleukin (IL)-4/IL-13 receptors, IL-4Ra, IL-13Ra1 and IL-13Ra2, have been identified in rainbow trout (Oncorhynchus mykiss) and have complex patterns of expression and modulation. Immunogenetics 2011;63(4):235-53.

38. Hong S, Li R, Xu Q, Secombes CJ, Wang T. Two types of TNF- $\alpha$ exist in teleost fish: Phylogeny, expression, and bioactivity analysis of type-II TNF- $\alpha 3$ in rainbow trout Oncorhynchus mykiss. Journal of Immunology 2013;191(12):5959-72.

39. Wang T, Husain M, Hong S, Holland JW. Differential expression, modulation and bioactivity of distinct fish IL-12 isoforms: Implication towards the evolution of Th1-like immune responses. European Journal of Immunology 2014;44(5):1541-51.

40. Tobback E, Decostere A, Hermans K, Haesebrouck F, Chiers K. Yersinia ruckeri infections in salmonid fish. Journal of Fish Diseases 2007;30(5):257-68.

41. Harun NO, Wang T, Secombes CJ. Gene expression profiling in naïve and vaccinated rainbow trout after Yersinia ruckeri infection: Insights into the mechanisms of protection seen in vaccinated fish. Vaccine 2011;29(26):4388-99.

42. Collins C, Hall M, Bruno D, Sokolowska J, Duncan L, Yuecel R, Mccarthy U, Fordyce MJ, Pert CC, Mcintosh R, Mackay Z. Generation of Paramoeba perurans clonal cultures using flow cytometry and confirmation of virulence. Journal of Fish Diseases 2016; doi:10.1111/jfd.12517.

43. Clifton-Hadley RS, Bucke D, Richards RH. A study of the sequential clinical and pathological changes during proliferative kidney disease in rainbow trout, Salmo gairdneri Richardson. Journal of Fish Diseases 1987;10(5):335-52.

44. Pfaffl MW. A new mathematical model for relative quantification in real-time RTPCR. Nucleic Acids Research 2001 MAY 1 2001;29(9):2002-7.

45. Crawley MJ. The R book. In: The R book. ; 2007. p 1-942.

46. Holm S. A simple sequentially rejective multiple test procedure. Scandinavian Journal of Statistics 1979;6(2):65-70.

47. Pfaffl MW, Horgan GW, Dempfle L. Relative expression software tool (REST) for group-wise comparison and statistical analysis of relative expression results in real-time PCR. Nucleic Acids Research 2002;30(9):1-10. 
48. Yang Z, Ming XF. Functions of arginase isoforms in macrophage inflammatory responses: Impact on cardiovascular diseases and metabolic disorders. Frontiers in Immunology 2014;5(533).

49. Ming XF, Rajapakse AG, Yepuri G, Xiong Y, Carvas JM, Ruffieux J, Scerri I, Wu Z, Popp K, Li J, Sartori C, Scherrer U, Kwak BR, Montani JP, Yang Z. Arginase II promotes macrophage inflammatory responses through mitochondrial reactive oxygen species, contributing to insulin resistance and atherogenesis. Journal of the American Heart Association 2012;1(4):e000992.

50. Amemiya CT, Alfoldi J, Lee AP, Fan S, Philippe H, MacCallum I, Braasch I, Manousaki T, Schneider I, Rohner N, Organ C, Chalopin D, Smith JJ, Robinson M, Dorrington RA, Gerdol M, Aken B, Biscotti MA, Barucca M, Baurain D, Berlin AM, Blatch GL, Buonocore F, Burmester T, Campbell MS, Canapa A, Cannon JP, Christoffels A, De Moro G, Edkins AL, Fan L, Fausto AM, Feiner N, Forconi M, Gamieldien J, Gnerre S, Gnirke A, Goldstone JV, Haerty W, Hahn ME, Hesse U, Hoffmann S, Johnson J, Karchner SI, Kuraku S, Lara M, Levin JZ, Litman GW, Mauceli E, Miyake T, Mueller MG, Nelson DR, Nitsche A, Olmo E, Ota T, Pallavicini A, Panji S, Picone B, Ponting CP, Prohaska SJ, Przybylski D, Saha NR, Ravi V, Ribeiro FJ, Sauka-Spengler T, Scapigliati G, Searle SMJ, Sharpe T, Simakov O, Stadler PF, Stegeman JJ, Sumiyama K, Tabbaa D, Tafer H, Turner-Maier J, Van Heusden P, White S, Williams L, Yandell M, Brinkmann H, Volff J-, Tabin CJ, Shubin N, Schartl M, Jaffe DB, Postlethwait JH, Venkatesh B, Di Palma F, Lander ES, Meyer A, Lindblad-Toh K. The african coelacanth genome provides insights into tetrapod evolution. Nature 2013;496(7445):311-6.

51. Mantovani A, Sica A, Sozzani S, Allavena P, Vecchi A, Locati M. The chemokine system in diverse forms of macrophage activation and polarization. Trends in Immunology 2004;25(12):677-86.

52. Martinez FO, Gordon S. The M1 and M2 paradigm of macrophage activation: Time for reassessment. F1000Prime Reports 2014;6(13):1-13.

53. Wang T, Secombes CJ. The evolution of IL-4 and IL-13 and their receptor subunits. Cytokine 2015;75(1):8-13.

54. Yamaguchi T, Miyata S, Katakura F, Nagasawa T, Shibasaki Y, Yabu T, Fischer U, Nakayasu C, Nakanishi T, Moritomo T. Recombinant carp IL-4/13B stimulates in vitro proliferation of carp IgM+ B cells. Fish \& Shellfish Immunology 2016;49:225-9. 
Table 1. Rainbow trout primer sequences used for PCR cloning and expression analysis (real time RTPCR).

\begin{tabular}{|c|c|c|c|c|c|c|}
\hline Gene & & Application & Oligonucleotides (5' - 3') & $\begin{array}{l}\text { Accession } \\
\text { Number }\end{array}$ & Ta $\left({ }^{\circ} \mathbf{C}\right)$ - Time (s) & Efficiency (\%) \\
\hline ef1a & $\begin{array}{l}\text { Forward } \\
\text { Reverse }\end{array}$ & $\begin{array}{l}\text { Real time } \\
\text { RT-PCR }\end{array}$ & $\begin{array}{l}\text { CAAGGATATCCGTCGTGGCA } \\
\text { ACAGCGAAACGACCAAGAGG }\end{array}$ & AF321836 & $63-30$ & $>99$ \\
\hline arg1a & $\begin{array}{l}\text { Forward } \\
\text { Reverse }\end{array}$ & PCR cloning & $\begin{array}{l}\text { ATTCTGAGCCGCTAACCCTTG } \\
\text { CACTGTAATCGAAAGGCTCTGTGG }\end{array}$ & & & \\
\hline arg1a & $\begin{array}{l}\text { Forward } \\
\text { Reverse }\end{array}$ & $\begin{array}{l}\text { Real time } \\
\text { RT-PCR }\end{array}$ & $\begin{array}{l}\text { CAGAGGTGGATCGCCTTGGAATA } \\
\text { GCAGACAGCATCCCTGTCTGACA }\end{array}$ & KX998965 & $66-20$ & $>94$ \\
\hline $\arg 1 b$ & $\begin{array}{l}\text { Forward } \\
\text { Reverse }\end{array}$ & PCR cloning & $\begin{array}{l}\text { GGCAAAGATGAGTTATGCAATTTTAGTG } \\
\text { TAATACAAAATATTGCGTTTGATGGC }\end{array}$ & & & \\
\hline $\arg 1 b$ & $\begin{array}{l}\text { Forward } \\
\text { Reverse }\end{array}$ & $\begin{array}{l}\text { Real time } \\
\text { RT-PCR }\end{array}$ & $\begin{array}{l}\text { AGGTGGATCGCCTTGGAATCG } \\
\text { GCAGACAGCAGCCCTGTCTGACT }\end{array}$ & KX998966 & $66-20$ & $>96$ \\
\hline $\arg 2 a$ & $\begin{array}{l}\text { Forward } \\
\text { Reverse }\end{array}$ & PCR cloning & $\begin{array}{l}\text { TCTCAGCCTTGGTCGTTAAAC } \\
\text { TGCCAAGTGGTCACATGTTGAAAG }\end{array}$ & & & \\
\hline $\arg 2 a$ & $\begin{array}{l}\text { Forward } \\
\text { Reverse }\end{array}$ & $\begin{array}{l}\text { Real time } \\
\text { RT-PCR }\end{array}$ & $\begin{array}{l}\text { TCCAGAGAGTCATGGAAGTCACTTTCC } \\
\text { CCATCACTGACAACAACCCTGTGTT }\end{array}$ & KX998967 & $66-20$ & $>96$ \\
\hline $\arg 2 b$ & $\begin{array}{l}\text { Forward } \\
\text { Reverse }\end{array}$ & PCR cloning & $\begin{array}{l}\text { GCAGCCTTGGTCGTTAAACGG } \\
\text { GCCAAGTGGTTACATGTTGAGTC }\end{array}$ & & & \\
\hline $\arg 2 b$ & $\begin{array}{l}\text { Forward } \\
\text { Reverse }\end{array}$ & $\begin{array}{l}\text { Real time } \\
\text { RT-PCR }\end{array}$ & $\begin{array}{l}\text { TCCAGAGAGTCATGGAAGTCTCTTTCG } \\
\text { CATCACCGACAACAACCCTGTGTT }\end{array}$ & KX998968 & $66-20$ & $>94$ \\
\hline
\end{tabular}

Table 2. Atlantic primer sequences used for gene expression analysis (real time RT-PCR).

\begin{tabular}{|c|c|c|c|c|c|}
\hline Gene & & Oligonucleotides $\left(5^{\prime}-3^{\prime}\right)$ & $\begin{array}{l}\text { Accession } \\
\text { Number }\end{array}$ & Ta $\left({ }^{\circ} \mathbf{C}\right)$ - Time (s) & Efficiency (\%) \\
\hline efla & $\begin{array}{l}\text { Forward } \\
\text { Reverse }\end{array}$ & $\begin{array}{l}\text { CAAGGATATCCGTCGTGGCA } \\
\text { ACAGCGAAACGACCAAGAGG }\end{array}$ & AF321836 & $63-30$ & $>99$ \\
\hline arg1a & $\begin{array}{l}\text { Forward } \\
\text { Reverse }\end{array}$ & $\begin{array}{l}\text { CAGAGGTGGATCGCCTTGGAATA } \\
\text { GCAGACAGCATCCCTGTCTGACA }\end{array}$ & XP_014013843.1 & $66-25$ & $>99$ \\
\hline $\arg 1 b$ & $\begin{array}{l}\text { Forward } \\
\text { Reverse }\end{array}$ & $\begin{array}{l}\text { AGGTGGATCGCCTTGGAATCG } \\
\text { CAGACAGCAGCCCTGTCTGACA }\end{array}$ & NP_001134788.1 & $66-25$ & $>86$ \\
\hline $\arg 2 a$ & $\begin{array}{l}\text { Forward } \\
\text { Reverse }\end{array}$ & $\begin{array}{l}\text { GACCACCTCTTGTCAAGGAAGCA } \\
\text { CTCACGGGTCTGTCCTAGGGC }\end{array}$ & XP_014045709.1 & $66-20$ & $>97$ \\
\hline $\arg 2 b$ & $\begin{array}{l}\text { Forward } \\
\text { Reverse }\end{array}$ & $\begin{array}{l}\text { GACCACCTCTTGTCAAGGAAGCA } \\
\text { CCATGGAAGCGGTGCTCG }\end{array}$ & XP_014067199.1 & $66-20$ & $>88$ \\
\hline
\end{tabular}


Table 3. Comparison of the amino acid identities/ similarities for arginase I and II using the Similarity Matrix BLOSUM62 within MatGat 2.02 software.

\begin{tabular}{|c|c|c|c|c|c|c|c|c|c|c|c|c|c|c|c|c|c|c|c|c|c|c|c|c|}
\hline & 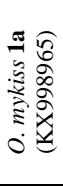 & 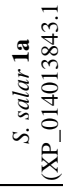 & 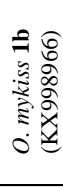 & 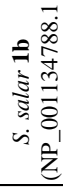 & 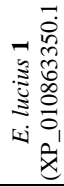 & 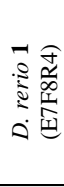 & 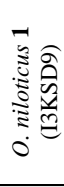 & 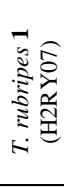 & 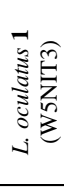 & 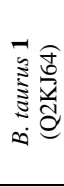 & 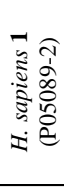 & 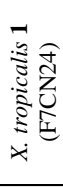 & 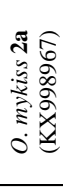 & 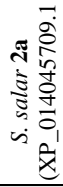 & 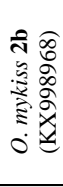 & 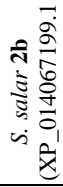 & 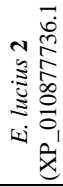 & 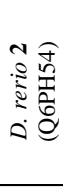 & 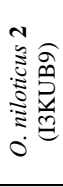 & 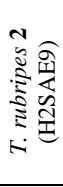 & 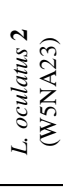 & 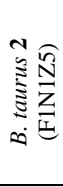 & 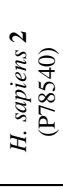 & 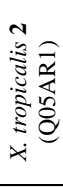 \\
\hline O. mykiss 1a (KX998965) & & 95.9 & 93.5 & 93.8 & 87.9 & 74.2 & 69.4 & 70.0 & 63.3 & $\begin{array}{lll}58.4 & & r\end{array}$ & 58.2 & 60.4 & $\begin{array}{llll}52.7 & & & \\
\end{array}$ & 52.7 & 53.0 & 52.7 & 53.8 & 53.0 & 51.1 & 53.2 & 46.8 & 52.8 & 54.8 & 53.9 \\
\hline S. salar 1a (XP_014013843.1) & 98.5 & & 93.2 & 93.5 & 87.9 & 75.1 & 68.7 & 69.1 & 62.9 & 57.2 & 58.2 & 60.1 & 51.9 & 51.9 & 52.6 & 52.9 & 53.5 & 53.0 & 50.6 & 52.9 & 46.3 & 52.8 & 54.2 & 53.9 \\
\hline O. mykiss 1b (KX998966) & 97.0 & 97.3 & & 97.9 & 91.1 & 77.1 & 67.5 & 69.1 & 62.8 & 58.0 & 58.4 & 60.2 & 52.9 & 52.9 & 53.2 & 53.4 & 53.6 & 53.3 & 51.3 & 53.0 & 47.4 & 53.1 & 54.5 & 53.9 \\
\hline S. salar 1b (NP_001134788.1) & 97.3 & 97.6 & 99.1 & & 91.4 & 77.1 & 68.1 & 69.7 & 62.8 & 57.4 & 57.8 & 59.6 & 52.3 & 52.3 & 52.6 & 52.9 & 53.0 & 52.7 & 50.7 & 52.7 & 46.9 & 53.7 & 55.1 & 53.6 \\
\hline E. lucius 1 (XP_010863350.1) & 95.6 & 95.9 & 96.4 & 96.7 & & 77.1 & 69.6 & 68.8 & 63.6 & 58.6 & 58.4 & 59.9 & 53.9 & 53.9 & 54.3 & 54.6 & 54.9 & 54.5 & 52.6 & 52.1 & 48.5 & 55.1 & 55.9 & 53.6 \\
\hline D. rerio 1 (E7F8R4) & 87.1 & 88.0 & 87.7 & 87.7 & 87.7 & & 67.1 & 66.5 & $\begin{array}{ll}59.4 \\
\end{array}$ & 56.1 & 57.1 & 56.0 & $\begin{array}{lll}50.7 & & \end{array}$ & 51.3 & 51.0 & 52.1 & 52.0 & 53.0 & 51.4 & 50.1 & 45.3 & 52.9 & 53.6 & $\begin{array}{ll}50.4 & \\
\end{array}$ \\
\hline O. niloticus 1 (I3KSD9) & 84.9 & 84.3 & 84.1 & 84.6 & 83.8 & 84.1 & & 71.0 & 58.4 & 55.5 & 55.4 & 55.7 & 51.6 & 51.1 & 51.6 & 51.3 & 51.8 & 51.6 & 51.0 & 51.9 & 44.9 & 50.8 & 52.1 & 51.1 \\
\hline T. rubripes 1 (H2RY07) & 82.2 & 81.9 & 82.2 & 82.5 & 81.6 & 79.6 & 81.7 & & 57.9 & 56.1 & 56.8 & 56.0 & 50.8 & 51.1 & 50.8 & 51.1 & 50.7 & 51.1 & 51.6 & 51.0 & 43.9 & 48.0 & 50.1 & 49.4 \\
\hline L. oculatus 1 (W5NIT3) & 77.4 & 77.4 & 77.7 & 77.4 & 77.7 & 76.1 & 75.0 & 74.5 & & 53.9 & 55.7 & 54.3 & 50.3 & 50.8 & 50.5 & 50.5 & 50.9 & 52.4 & 51.6 & 51.4 & 46.4 & 49.6 & 51.2 & 51.9 \\
\hline B. taurus 1 (Q2KJ64) & 72.5 & 72.2 & 72.4 & 72.1 & 73.3 & 71.6 & 71.0 & 72.3 & 67.7 & & 88.8 & 68.1 & 53.9 & 53.3 & 53.6 & 54.2 & 54.4 & 53.6 & 54.0 & 54.4 & 46.3 & 54.0 & 54.5 & 53.9 \\
\hline H. sapiens 1 (P05089-2) & 74.0 & 74.6 & 74.2 & 73.9 & 74.2 & 74.2 & 73.0 & 73.5 & 69.0 & 92.7 & & 66.8 & 51.8 & 51.0 & 51.5 & 52.1 & 52.5 & 53.8 & 52.8 & 52.9 & 47.5 & 53.9 & 53.3 & 53.3 \\
\hline X. tropicalis 1 (F7CN24) & 76.0 & 75.4 & 75.1 & 75.7 & 75.4 & 75.4 & 72.8 & 73.8 & 71.2 & 80.7 & 80.9 & & 53.0 & 53.3 & 52.7 & 53.3 & 52.9 & 53.3 & 52.9 & 53.0 & 45.5 & 51.4 & 52.3 & 53.1 \\
\hline O. mykiss 2a (KX998967) & 69.2 & 69.2 & 69.5 & 69.2 & 68.9 & 69.5 & 68.6 & 68.9 & 66.8 & 68.9 & 69.7 & 71.2 & & 96.0 & 95.4 & 94.8 & 88.8 & 79.8 & 78.9 & 73.2 & 64.3 & 62.4 & 62.1 & 61.7 \\
\hline S. salar 2a (XP_014045709.1) & 69.5 & 69.5 & 69.5 & 69.2 & 69.2 & 69.7 & 68.9 & 69.5 & 67.7 & 68.9 & 68.3 & 71.8 & 98.0 & & 93.7 & 95.4 & 88.5 & 79.3 & 79.1 & 73.2 & 65.0 & 63.8 & 63.8 & 63.1 \\
\hline O. mykiss 2b (KX998968) & 70.0 & 70.6 & 70.3 & 70.0 & 70.0 & 69.7 & 68.9 & 68.9 & 67.7 & 69.2 & 70.0 & 71.8 & 97.4 & 97.1 & & 97.7 & 89.9 & 81.0 & 80.6 & 73.0 & 65.0 & $\begin{array}{ll}62.4 \\
\end{array}$ & 62.4 & 62.5 \\
\hline S. salar 2b (XP_014067199.1) & 70.0 & 70.6 & 70.3 & 70.0 & 70.0 & 70.0 & 68.9 & 68.9 & 67.4 & 69.2 & 70.0 & 71.8 & 98.0 & 97.7 & 99.4 & & 90.2 & 81.0 & 80.9 & 73.2 & 65.5 & 64.1 & 64.1 & 63.6 \\
\hline E. lucius 2(XP_010877736.1) & 71.7 & 70.8 & 71.1 & 70.8 & 71.4 & 72.0 & 70.8 & 70.2 & 69.6 & 69.9 & 69.9 & 72.3 & 94.2 & 95.1 & 94.5 & 95.4 & & 79.9 & 78.6 & 72.4 & 65.0 & 63.3 & 63.6 & 62.8 \\
\hline D. rerio 2 (Q6PH54) & 70.9 & 70.3 & 69.5 & 69.2 & 70.3 & 71.2 & 68.0 & 68.0 & 67.7 & 68.6 & 69.2 & 70.9 & 91.4 & 91.1 & 91.9 & 91.9 & 91.6 & & 79.7 & 74.4 & 67.3 & 60.7 & 61.0 & 63.3 \\
\hline O. niloticus 2 (I3KUB9) & 70.6 & 69.7 & 70.3 & 70.0 & 70.3 & 71.7 & 68.0 & 70.0 & 68.2 & 69.4 & 70.3 & 69.1 & 87.1 & 87.4 & 88.0 & 88.3 & 87.7 & 88.9 & & 76.2 & 64.4 & 62.5 & 63.0 & 63.2 \\
\hline T. rubripes 2 (H2SAE9) & 70.1 & 69.6 & 69.6 & 69.0 & 69.3 & 68.2 & 67.3 & 67.6 & 67.4 & 69.6 & 70.1 & 69.3 & 83.7 & 83.7 & 84.5 & 84.5 & 83.4 & 84.2 & 87.6 & & 58.9 & 63.2 & 63.2 & 63.3 \\
\hline L. oculatus 2 (W5NA23) & 61.3 & 61.0 & 61.5 & 60.8 & 60.5 & 62.0 & 59.5 & 59.0 & 62.5 & 57.3 & 58.8 & 61.0 & 75.5 & 75.5 & 75.8 & 76.3 & 76.8 & 76.3 & 76.0 & 72.5 & & 56.4 & 56.6 & 58.8 \\
\hline B. taurus 2 (F1N1Z5) & 69.2 & 69.5 & 69.2 & 68.9 & 70.1 & 70.3 & 68.9 & 65.8 & 67.9 & 68.4 & 69.2 & 69.8 & 78.8 & 79.9 & 79.4 & 79.7 & 79.4 & 79.4 & 80.2 & 79.4 & 73.0 & & 92.7 & 71.4 \\
\hline H. sapiens 2 (P78540) & 69.8 & 69.5 & 69.8 & 69.5 & 70.9 & 71.2 & 70.6 & 66.7 & 68.5 & 67.8 & 68.1 & 69.2 & 79.4 & 80.2 & 79.7 & 79.9 & 79.9 & 79.4 & 79.4 & 79.4 & 74.0 & 96.9 & & 71.7 \\
\hline X. tropicalis $2(\mathrm{Q} 05 \mathrm{AR} 1)$ & 66.9 & 66.7 & 67.8 & 67.2 & 67.2 & 67.5 & 66.7 & 64.4 & 66.8 & 65.6 & 66.7 & 67.2 & 75.6 & 76.4 & 75.6 & 76.1 & 75.0 & 75.6 & 74.7 & 76.9 & 72.5 & 85.6 & 84.4 & \\
\hline
\end{tabular}


\begin{tabular}{|l|l|}
\hline Identity & Similarity \\
\hline
\end{tabular} 
Figure 1

2

S. salar 1a

(Chr. 19)
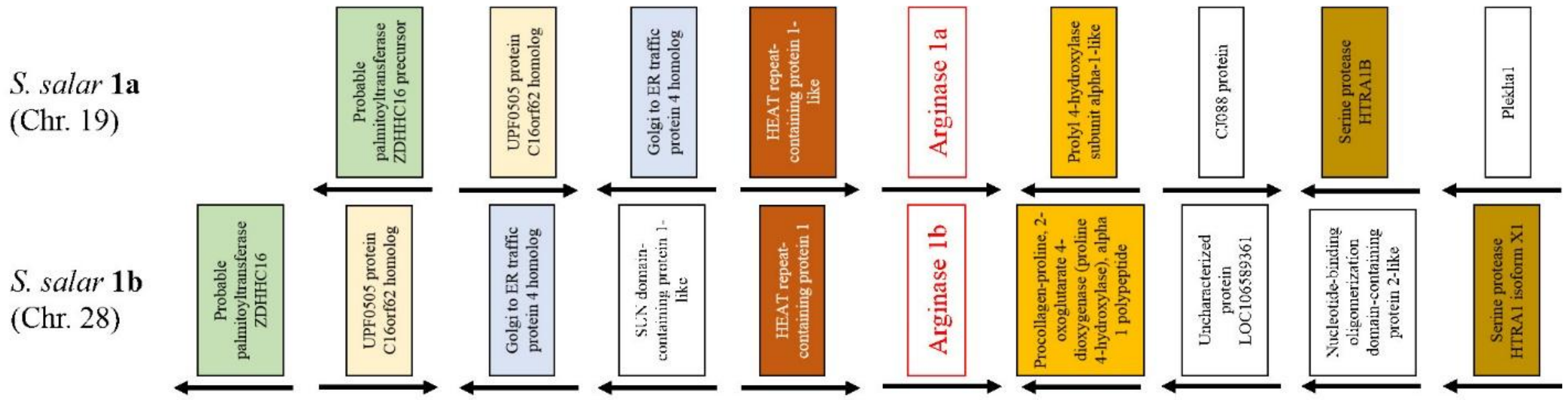

S. salar 2a

(Chr. 01)

S. salar $\mathbf{2 b}$

(Chr. 09)
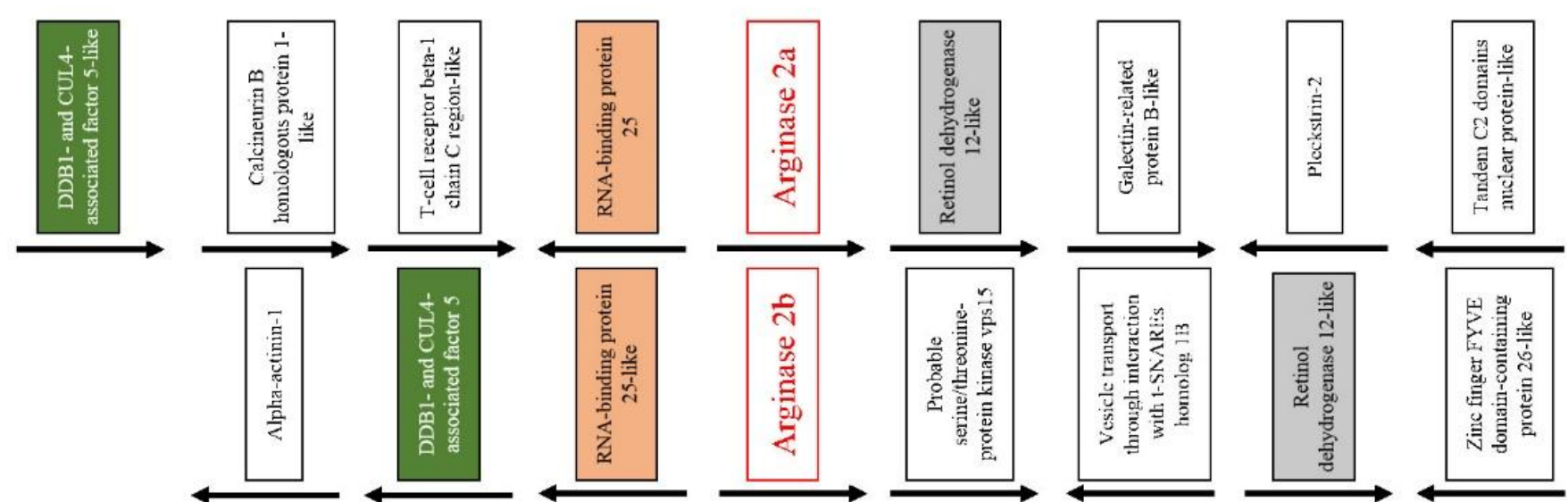
$5 \quad$ Figure 2.

6 (A)

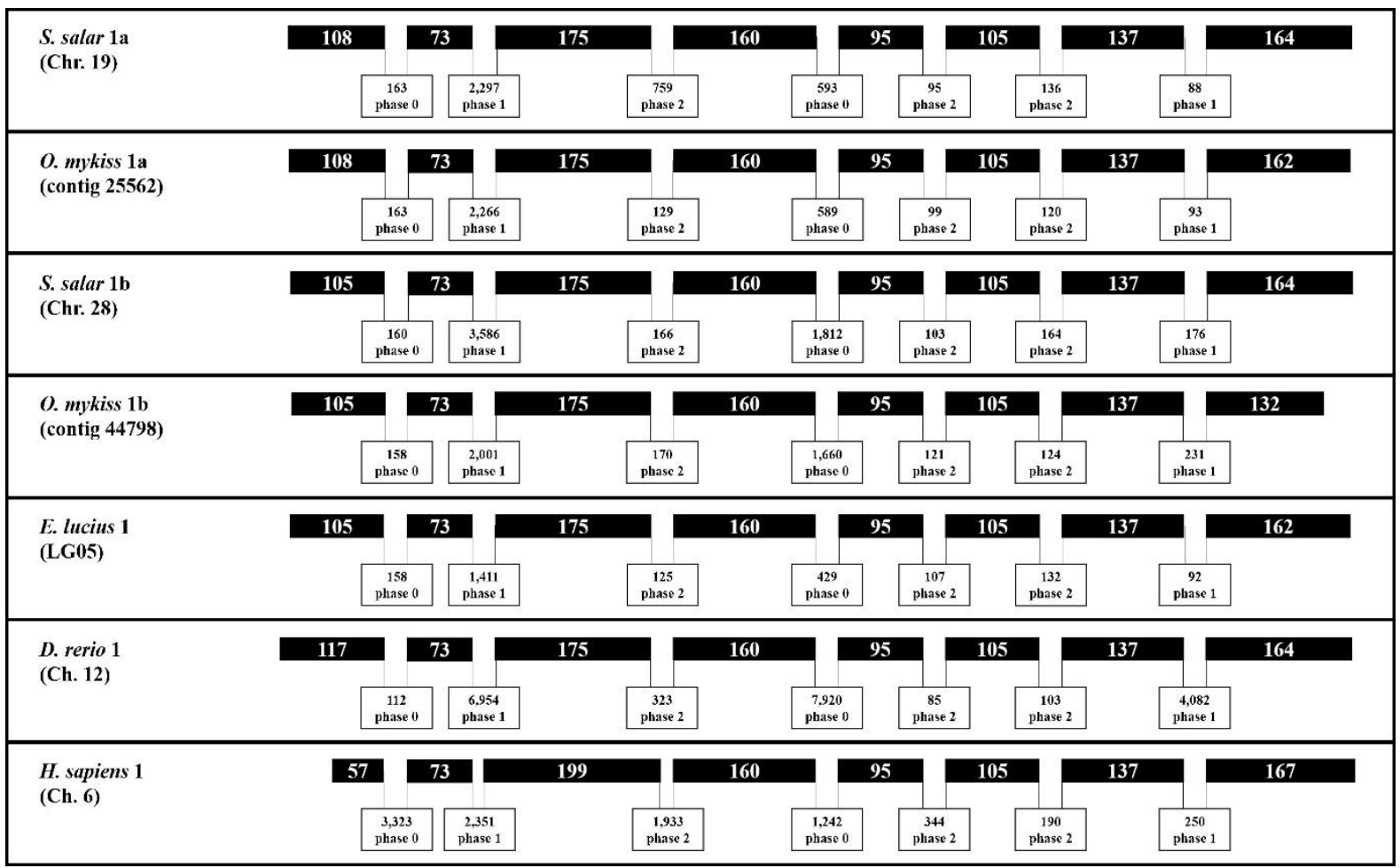

$8 \quad$ (B)

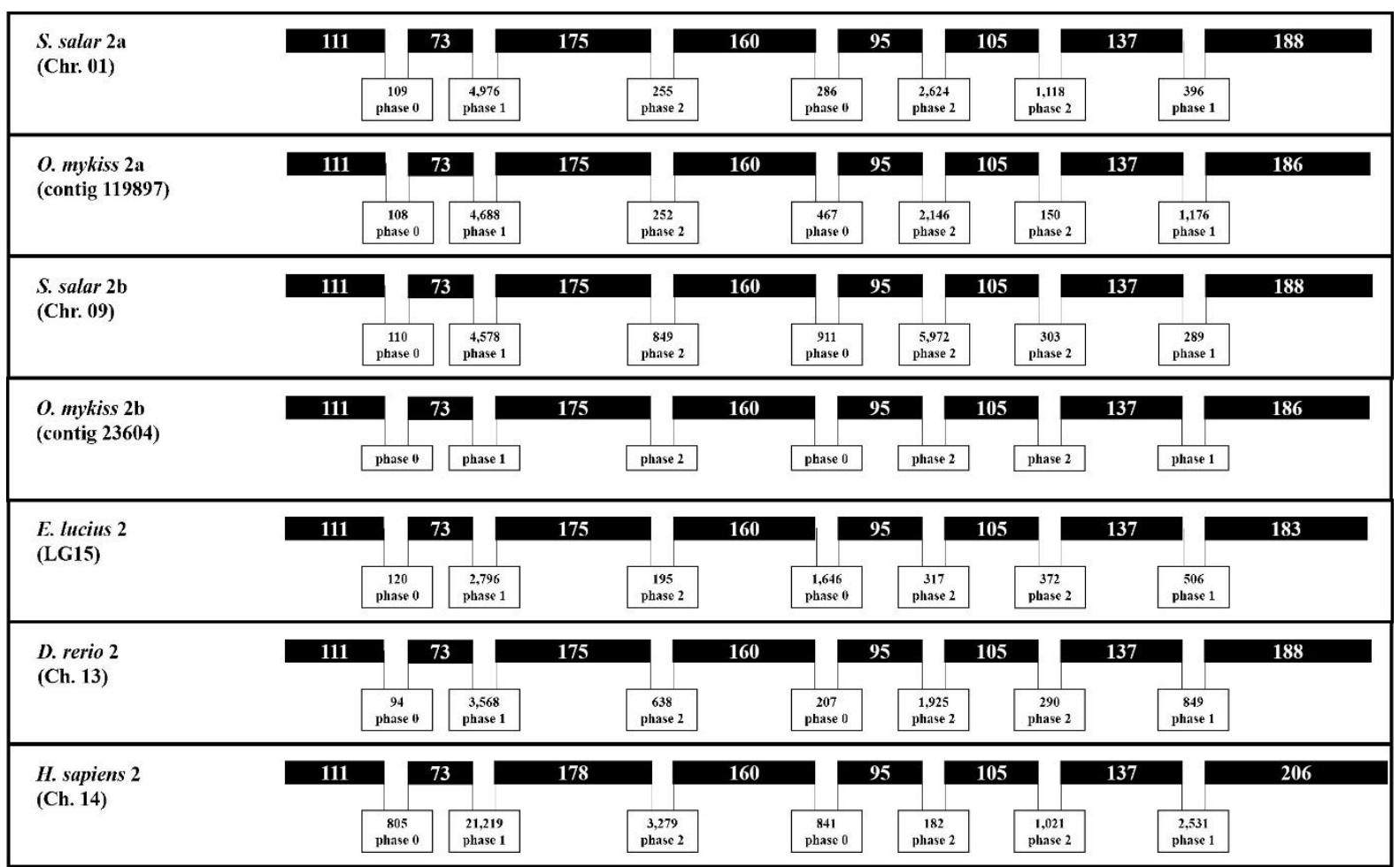


Figure 3.

\section{Tissue distribution}

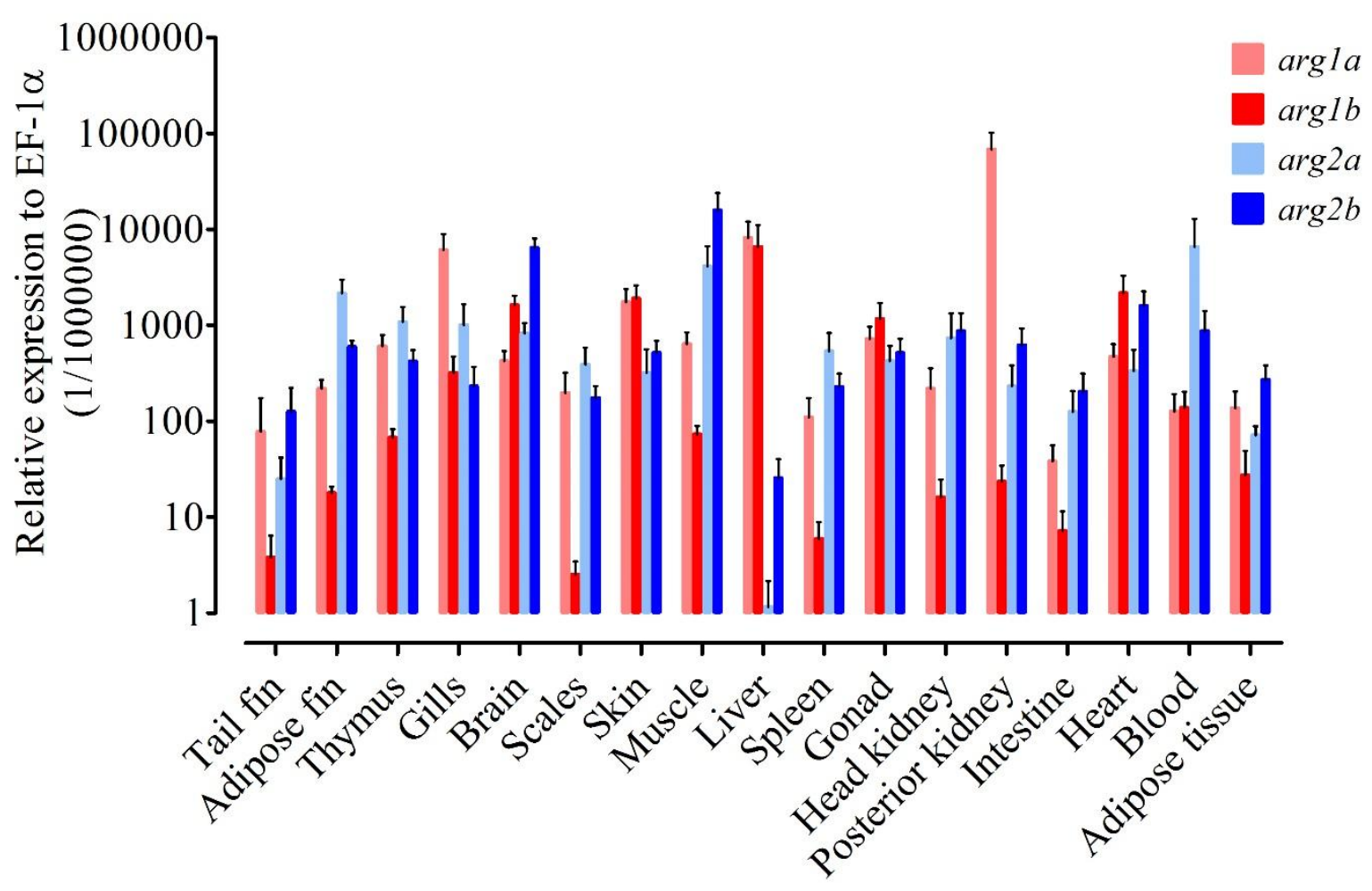


Figure 4.
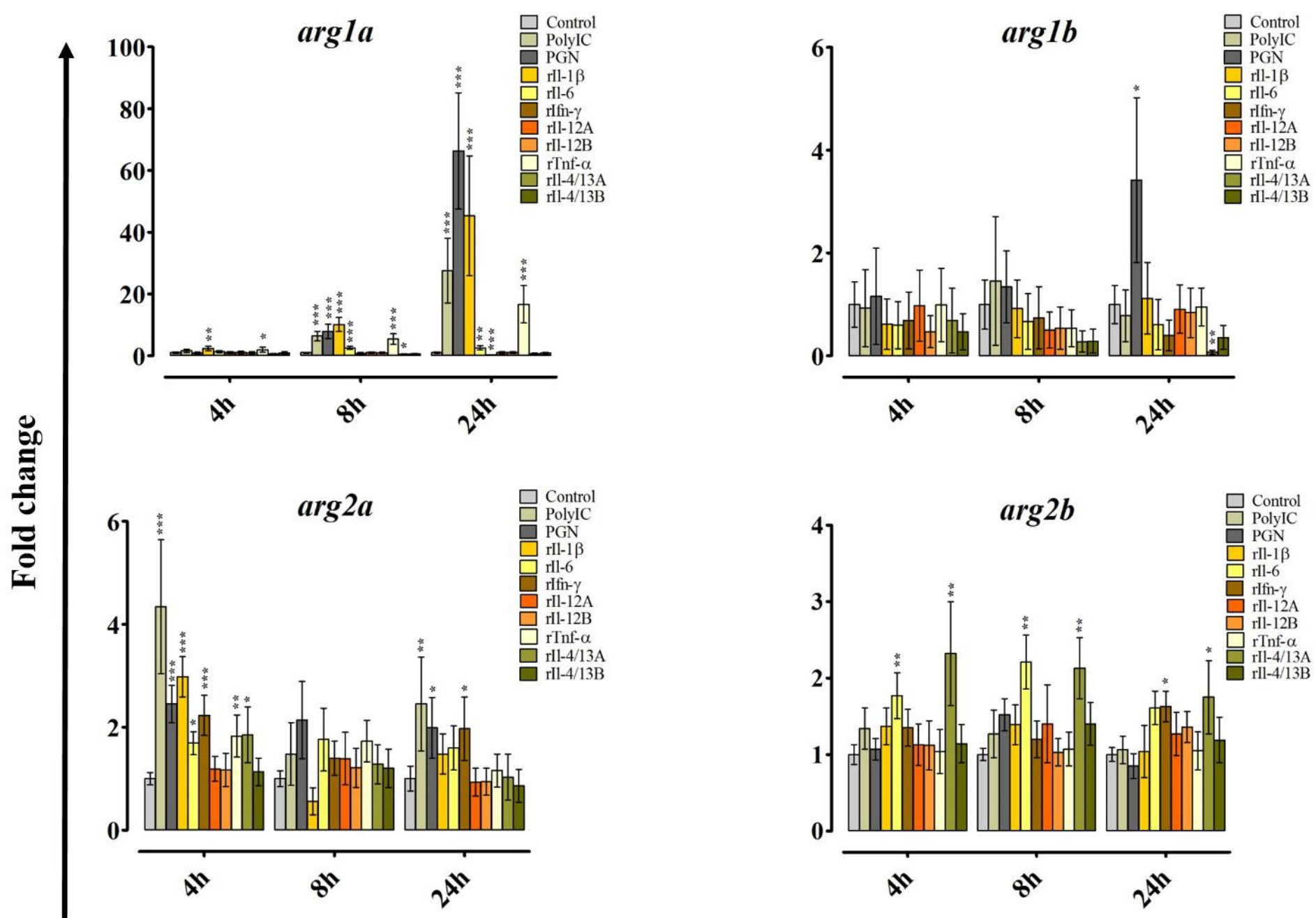
Figure 5.

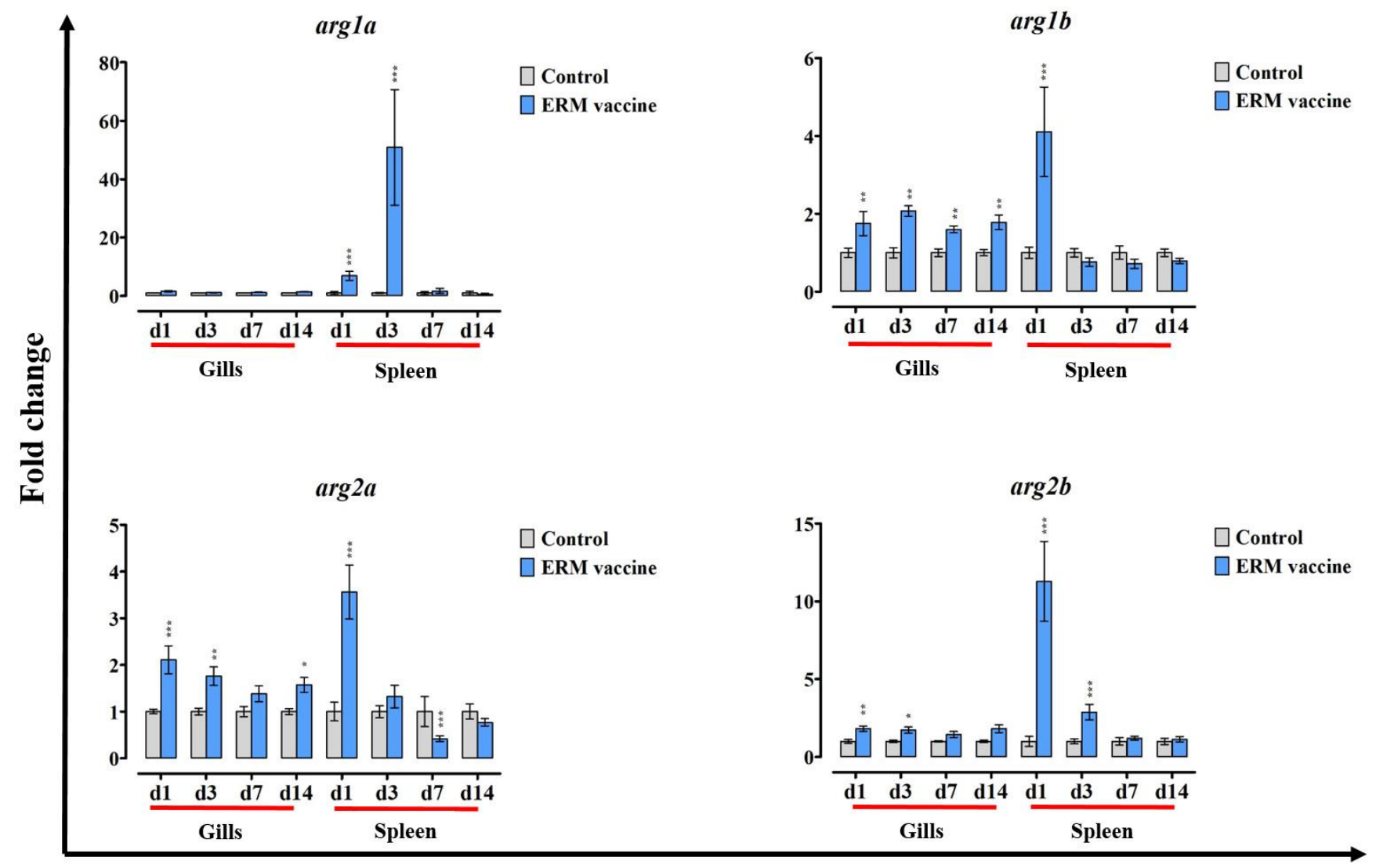




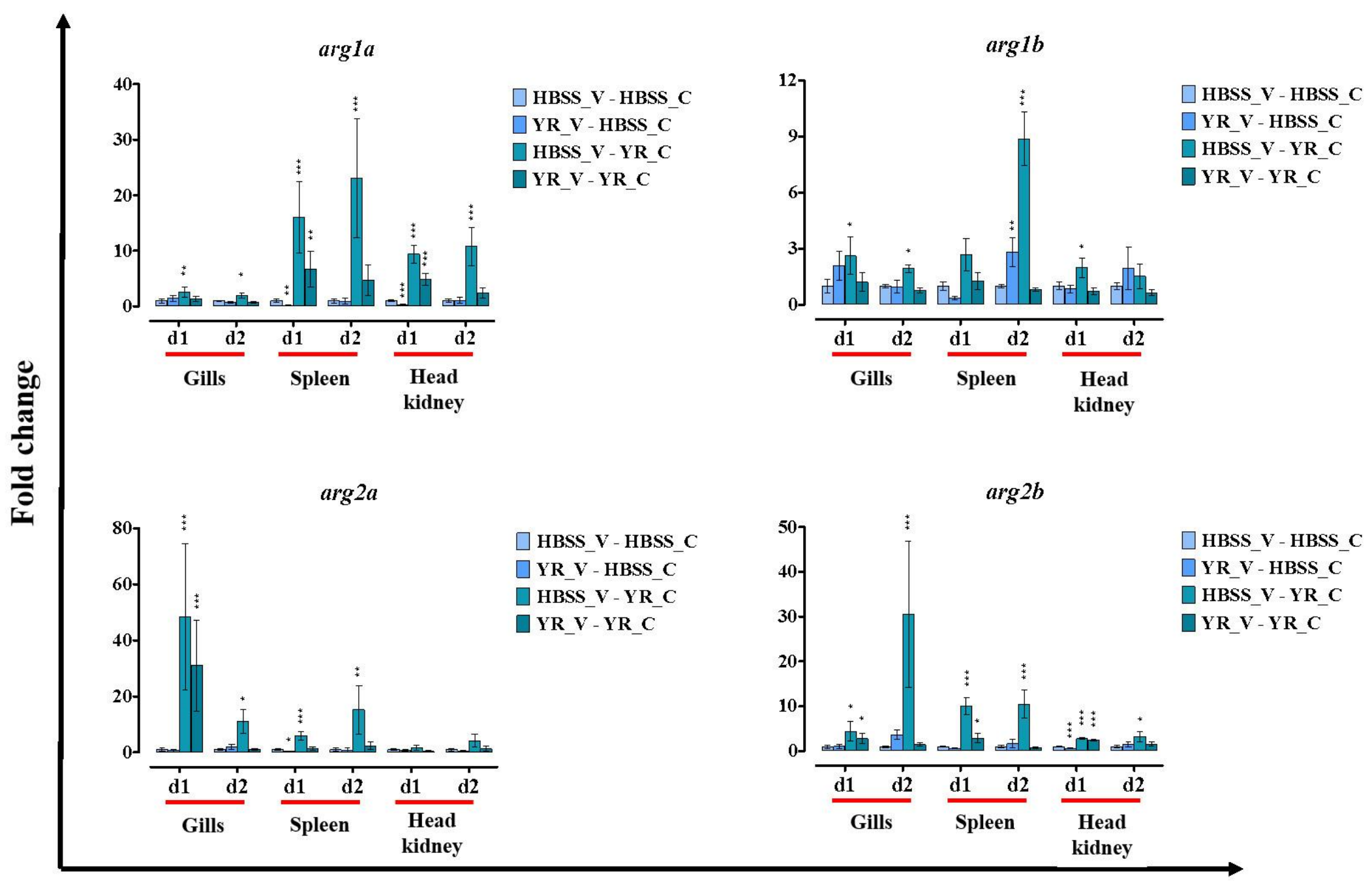

Time and tissues 
Figure 7.

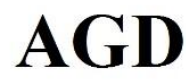

Culture media

Polyclonal 500 cells/1

Polyclonal 5000 cells/1

B8 clone 500 cells/ 1

B8 clone 5000 cells/ 1

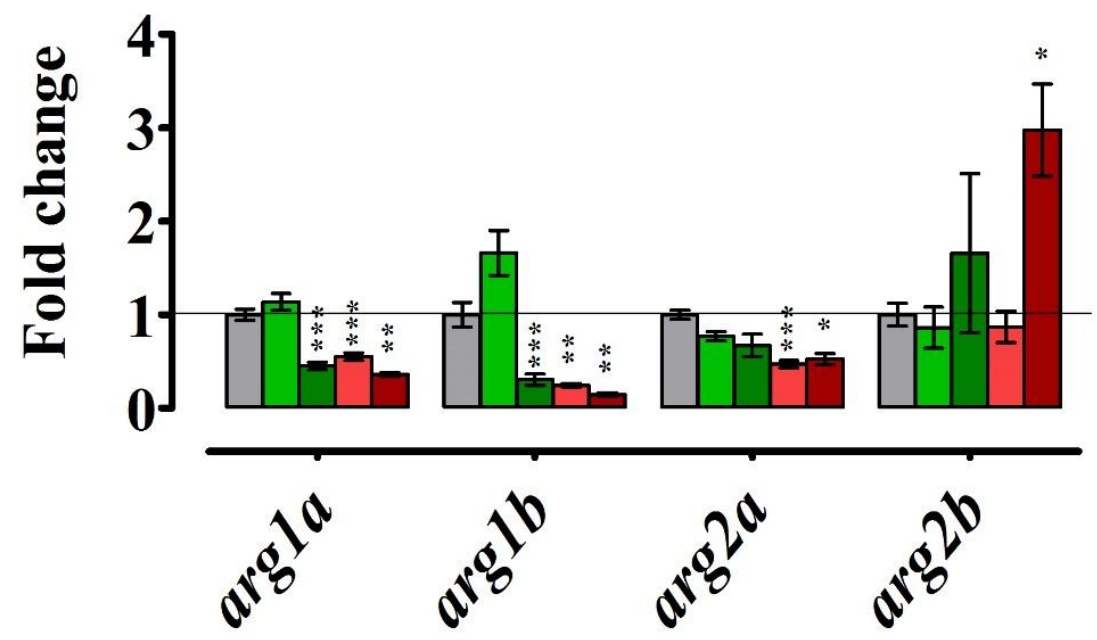

Figure 8.
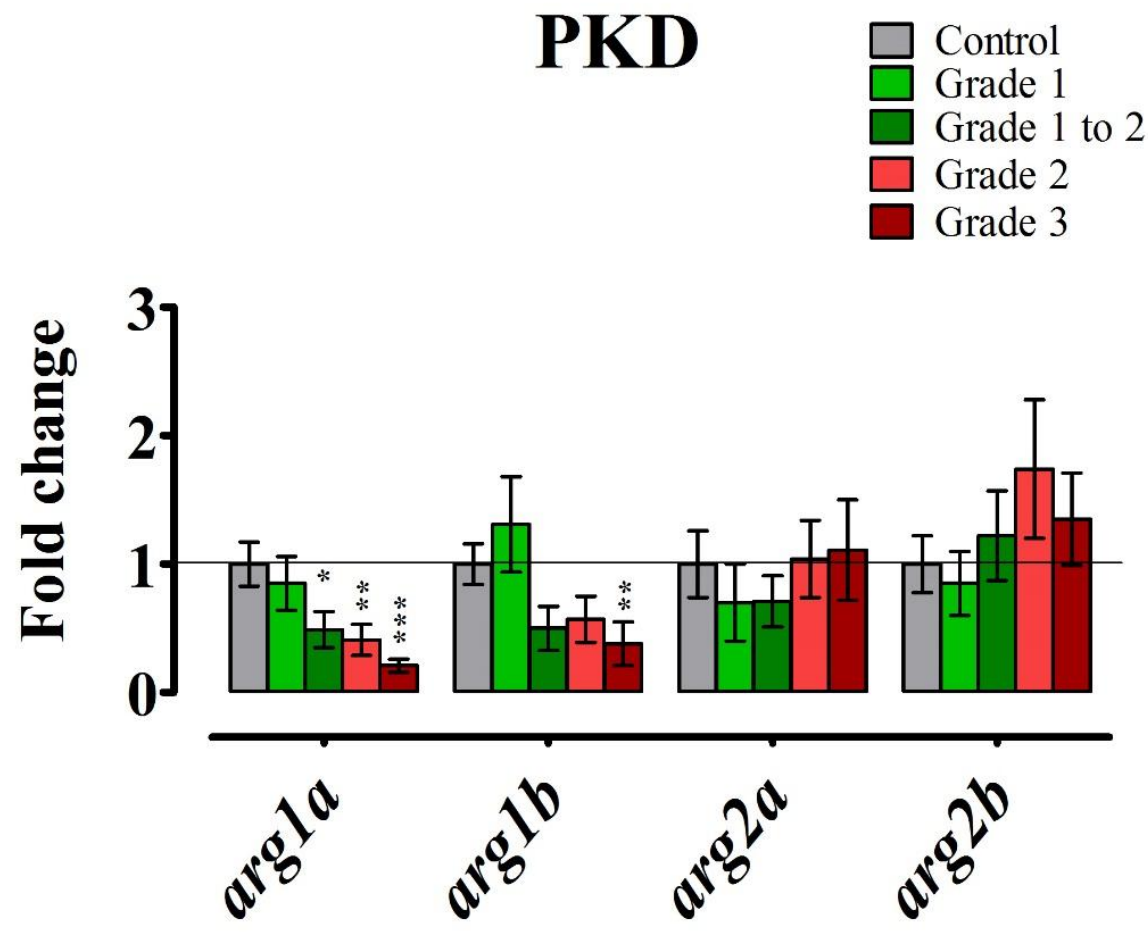